\title{
The diagnostic accuracy of serological tests for Lyme borreliosis in Europe: a systematic review and meta-analysis
}

M. M. G. Leeflang ${ }^{12 *}$, C. W. Ang ${ }^{1}$, J. Berkhout ${ }^{2}$, H. A. Bijlmer ${ }^{3}$, W. Van Bortel ${ }^{4}$, A. H. Brandenburg ${ }^{5}$, N. D. Van Burgel ${ }^{6}$, A. P. Van Dam7, R. B. Dessau', V. Fingerle9, J. W. R. Hovius ${ }^{10}$, B. Jaulhac ${ }^{11}$, B. Meijer ${ }^{13}$, W. Van Pelt ${ }^{3}$, J. F. P. Schellekens ${ }^{13}$, R. Spijker ${ }^{14}$, F. F. Stelma ${ }^{15}$, G. Stanek ${ }^{16}$, F. Verduyn-Lunel ${ }^{17}$, H. Zeller ${ }^{4}$ and H. Sprong ${ }^{3}$

\begin{abstract}
Background: Interpretation of serological assays in Lyme borreliosis requires an understanding of the clinical indications and the limitations of the currently available tests. We therefore systematically reviewed the accuracy of serological tests for the diagnosis of Lyme borreliosis in Europe.

Methods: We searched EMBASE en MEDLINE and contacted experts. Studies evaluating the diagnostic accuracy of serological assays for Lyme borreliosis in Europe were eligible. Study selection and data-extraction were done by two authors independently. We assessed study quality using the QUADAS-2 checklist. We used a hierarchical summary ROC meta-regression method for the meta-analyses. Potential sources of heterogeneity were test-type, commercial or in-house, Ig-type, antigen type and study quality. These were added as covariates to the model, to assess their effect on test accuracy.
\end{abstract}

Results: Seventy-eight studies evaluating an Enzyme-Linked ImmunoSorbent assay (ELISA) or an immunoblot assay against a reference standard of clinical criteria were included. None of the studies had low risk of bias for all QUADAS-2 domains. Sensitivity was highly heterogeneous, with summary estimates: erythema migrans $50 \%$ (95\% Cl 40 \% to $61 \%$ ); neuroborreliosis $77 \%$ (95\% Cl $67 \%$ to $85 \%$ ); acrodermatitis chronica atrophicans $97 \%$ (95\% Cl $94 \%$ to $99 \%$ ); unspecified Lyme borreliosis $73 \%$ (95\% Cl $53 \%$ to $87 \%$ ). Specificity was around $95 \%$ in studies with healthy controls, but around $80 \%$ in cross-sectional studies. Two-tiered algorithms or antibody indices did not outperform single test approaches.

Conclusions: The observed heterogeneity and risk of bias complicate the extrapolation of our results to clinical practice. The usefulness of the serological tests for Lyme disease depends on the pre-test probability and subsequent predictive values in the setting where the tests are being used. Future diagnostic accuracy studies should be prospectively planned cross-sectional studies, done in settings where the test will be used in practice.

Keywords: Lyme borreliosis, serology, sensitivity and specificity, meta-analysis

\footnotetext{
* Correspondence: m.m.leeflang@amc.uva.nl

${ }^{12}$ Department of Clinical Epidemiology, Biostatistics and Bioinformatics,

Academic Medical Center, University of Amsterdam, PO Box 22700, 1100 DE

Amsterdam, The Netherlands

Full list of author information is available at the end of the article
} 


\section{Background}

Lyme borreliosis is one of the most prevalent vectorborne diseases in Europe. Its incidence varies between countries, with approximately 65,500 patients annually in Europe (estimated in 2009) [1]. It is caused by spirochetes of the Borrelia burgdorferi sensu lato species complex, which are transmitted by several species of Ixodid ticks [2]. In Europe, at least five genospecies of the Borrelia burgdorferi sensu lato complex can cause disease, leading to a variety of clinical manifestations including erythema migrans (EM), neuroborreliosis, arthritis and acrodermatitis chronica atrophicans (ACA). Each of these clinical presentations can be seen as a distinct target condition, i.e. the disorder that a test tries to determine, as they affect different body parts and different organ systems, and because the patients suffering from these conditions may enter and travel through the health care system in different ways, hence following different clinical pathways.

The diagnosis of Lyme borreliosis is based on the presence of specific symptoms, combined with laboratory evidence for infection. Laboratory confirmation is essential in case of non-specific disease manifestations. Serology is the cornerstone of Lyme laboratory diagnosis, both in primary care and in more specialized settings. Serological tests that are most often used are enzyme-linked immunosorbent assays (ELISAs) or immunoblots. ELISAs are the first test to be used; immunoblots are typically applied only when ELISA was positive. If signs and symptoms are inconclusive, the decision may be driven by the serology test results. In such a situation, patients may be treated with antibiotics after a positive serology result - a positive ELISA possibly followed by a positive immunoblot. After negative serology - a negative ELISA or a positive ELISA followed by a negative immunoblot - patients will not be treated for Lyme borreliosis, but they will be followed up or referred for further diagnosis. This implies that false positively tested patients (who have no Lyme borreliosis, but have positive serology) will be treated for Lyme borreliosis while they have another condition. It also implies that falsely negative tested patients (who have the disease, but test negative) will not be treated for Lyme borreliosis. A test with a high specificity - which is the percentage true negative results among patients without the target condition - will result in a low percentage of false positives. A test with a high sensitivity - being the percentage true positives among patients with the target condition will result in a low percentage of false negatives.

The interpretation of serology results is complicated. The link between antibody status and actual infection may not be obvious: non-infected people may have immunity and test positive, while infected people may have a delay in their antibody response and may test negative. Furthermore, there is an overwhelming number of different available assays that have all been evaluated in different patient populations and settings and that may perform differently for the various disease manifestations [3]. We therefore systematically reviewed all available literature to assess the accuracy (expressed as sensitivity and specificity) of serological tests for the diagnosis of the different manifestations of Lyme borreliosis in Europe. Our secondary aim was to investigate potential sources of heterogeneity, for example test-type, whether the test was a commercial test or an inhouse test, publication year and antigens used.

\section{Methods}

We searched EMBASE and Medline (Appendix 1) and contacted experts for studies evaluating serological tests against a reference standard. The reference standard is the test or testing algorithm used to define whether someone has Lyme borreliosis or not. We included studies using any reference standard, but most studies used clinical criteria, sometimes in combination with serology. Studies performed in Europe and published in English, French, German, Norwegian, Spanish and Dutch were included.

The ideal study type to answer our question would be a cross-sectional study, including a series of representative, equally suspected patients who undergo both the index test and the reference standard [4]. Such studies would provide valid estimates of sensitivity and specificity and would also directly provide estimates of prevalence and predictive values. However, as we anticipated that these cross-sectional studies would be very sparse, we decided to include case-control studies or so-called two-gate designs as well [5]. These studies estimate the sensitivity of a test in a group of cases, i.e. patients for whom one is relatively sure that they have Lyme borreliosis. They estimate the specificity in a group of controls, i.e. patients of whom one is relatively sure that they do not have Lyme borreliosis. These are healthy volunteers, or patients with other diseases than Lyme.

We included studies on ELISAs, immunoblots, two-tiered testing algorithms of an ELISA followed by an immunoblot, and specific antibody index measurement (calculated using the antibody titers in both serum and cerebrospinal fluid). We excluded indirect fluorescent antibody assays, as these are rarely used in practice. Studies based on make-up samples were excluded. We also excluded studies for which $2 \times 2$ tables could not be inferred from the study results.

For each article, two authors independently collected study data and assessed quality. We assessed the quality using the Quality Assessment of Diagnostic Accuracy Studies-2 (QUADAS-2) checklist. This checklist consists of four domains: patient selection, index test, reference standard and flow and timing [6]. Each of these domains has a sub-domain for risk of bias and the first three have a sub-domain for concerns regarding the applicability of study results. The sub-domains about risk of bias include a number of signalling questions to guide the overall 
judgement about whether a study is highly likely to be biased or not (Appendix 2).

We analysed test accuracy for each of the manifestations of Lyme borreliosis separately and separately for case-control designs and cross-sectional designs. If a study did not distinguish between the different manifestations, we used the data of this study in the analysis for the target condition "unspecified Lyme". Serology assays measure the level of immunoglubulins (Ig) in the patient's serum. IgM is the antibody most present in the early stages of disease, while IgG increases later in the disease. Some tests only measure IgM, some only IgG and some tests measure any type of Ig. In some studies, the accuracy was reported for IgM only, IgG only and for detection of IgG and IgM. In those cases, we included the data for simultaneous detection of both IgG and IgM (IgT).

We meta-analyzed the data using the Hierarchical Summary ROC (HSROC) model, a hierarchical metaregression method incorporating both sensitivity and specificity while taking into account the correlation between the two [7]. The model assumes an underlying summary ROC curve through the study results and estimates the parameters for this curve: accuracy, threshold at which the tests are assumed to operate and shape of the curve. Accuracy is a combination of sensitivity and specificity; the shape of the curve provides information about how accuracy varies when the threshold varies. From these parameters we derived the reported sensitivity and specificity estimates. We used SAS 9.3 for the analyses and Review Manager 5.3 for the ROC plots.

There is no recommended measure to estimate the amount of heterogeneity in diagnostic accuracy reviews, but researchers are encouraged to investigate potential sources of heterogeneity [7]. The most prominent source of heterogeneity is variation in threshold, which is taken into account by using the HSROC model. Other potential sources of heterogeneity are: test type (ELISA or immunoblot); a test being commercial or not; immunoglobulin type; antigen used; publication year; late versus early disease; and study quality. These were added as covariates to the model to explain variation in accuracy, threshold or shape of the curve.

Some studies reported results for patients with "possible Lyme" (i.e. no clear cases, neither clear controls). We included these as cases. As this may lead to underestimation of sensitivity, we investigated the effect of this approach. Borderline test results were included in the test-positive group.

\section{Results}

\section{Selection and quality assessment}

Our initial search in January 2013 retrieved 8026 unique titles and a search update in February 2014 revealed another 418 titles. After careful selection by two authors independently (ML, HS) we read the full text of 489 studies, performed data-extraction on 122 studies and finally included 75 unique published articles (Fig. 1). Fifty-seven of these had a case-control design, comparing a group of well-defined cases with a group of healthy controls or controls with diseases that could lead to cross-reactivity of the tests [8-64]. Eighteen had a crosssectional design in which a more homogeneous sample of patients underwent both the serological assay(s) and the reference standard [65-82]. Three studies were not used in the meta-analyses, either because they used immunoblot as a reference standard [76, 79], or included asymptomatic cross-country runners with high IgG titers as controls [47].

None of the studies had low risk of bias in all four QUADAS-2 domains (Fig. 2 and Tables 1 and 2). Fortysix out of the 57 case-control studies and six out of the 18 cross-sectional studies scored unclear or high risk of bias in all four domains. All case-control studies had a high risk of bias for the patient sampling domain, because these designs exclude all "difficult to diagnose" patients [83]. Only three studies reported that the assessment of the index test was blinded for the disease status of the participants $[45,66,75]$. The cut-off value to decide whether a test is positive or negative was often decided after the study was done, which may also lead to bias in the index test domain [84]. The most common problem was inclusion of the serology results in the reference standard. The flow and timing domain was problematic in all case-control studies, as the cases and controls are usually verified in different ways. Three studies reported potential conflict of interest [31, 39, 62]. Most studies had a high concern regarding applicability, which means that either the included patients or the test used are not representative for clinical practice. Only three studies were representative for all domains $[65,73,81]$.

\section{Meta-analyses Erythema migrans}

Nineteen case-control studies including healthy controls evaluated the accuracy of serological tests for EM. The summary sensitivity for ELISA or immunoblot detecting EM patients was $50 \%$ (95\% CI $40 \%$ to $61 \%$ ) and specificity $95 \%$ (95\% CI $92 \%$ to $97 \%$ ). ELISA tests had a higher accuracy than immunoblots $(P$-value $=0 \cdot 008)$, mainly due to a higher sensitivity (Table 3 ). Commercial tests did not perform significantly different from in-house tests. The 23 case-control studies on EM including cross-reacting controls had similar results (data not shown). One crosssectional study done on EM-suspected patients evaluated four different immunoblots in patients with a positive or unclear ELISA result; their sensitivity varied between 33 and $92 \%$ and their specificity between 27 and $70 \%$ [66]. 


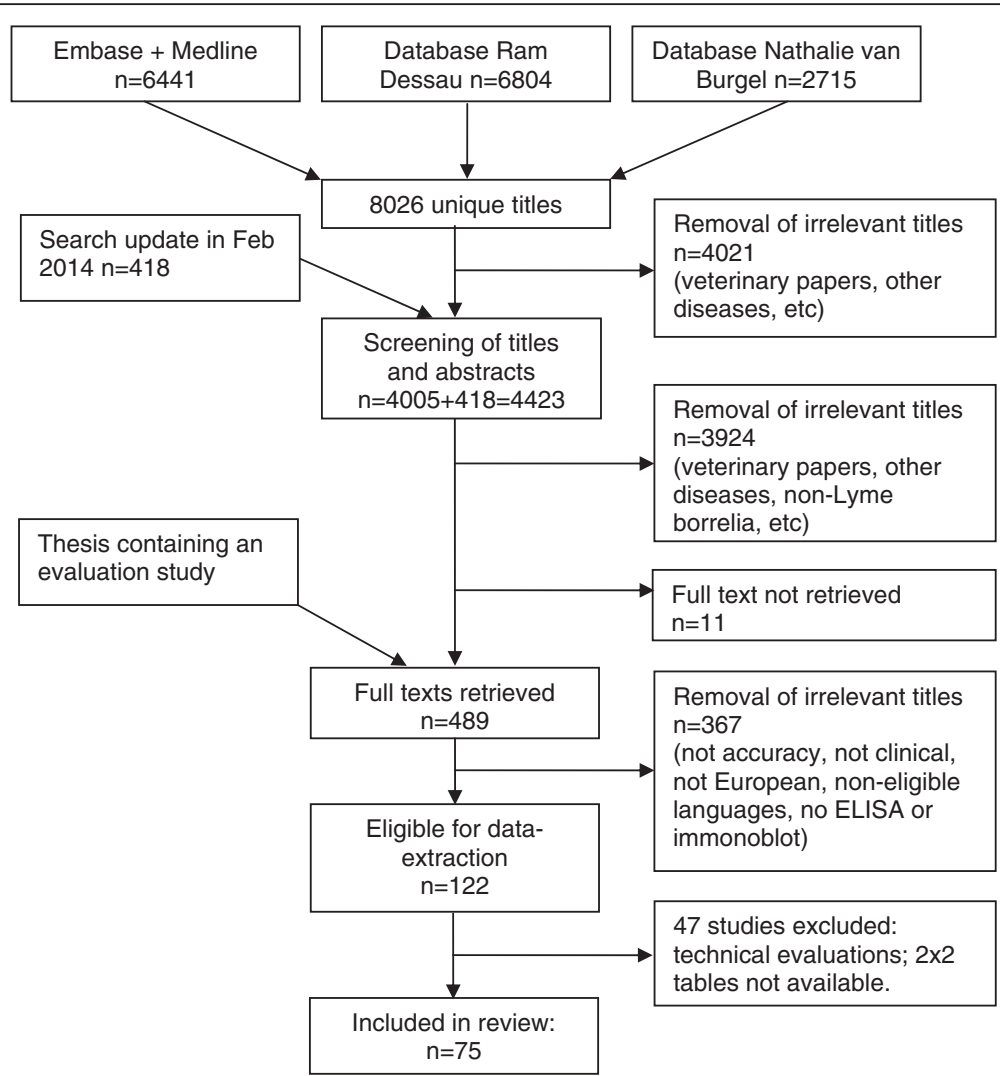

Fig. 1 Results of the search and selection process

\section{Neuroborreliosis}

Twenty case-control studies on neuroborreliosis included healthy controls. Their overall sensitivity was $77 \%$ (95\% CI $67 \%$ to $85 \%$ ) and their specificity $93 \%$ (95\% CI $88 \%$ to $96 \%$ ) (Fig. 3a). On average, ELISA assays had a lower accuracy than immunoblot assays $(P=0 \cdot 042)$. The in-house ELISAs had the lowest specificity of all tests (Table 3). Twenty-six case-control studies with crossreacting controls showed similar results, but with a lower specificity (data not shown). The ten cross-sectional studies

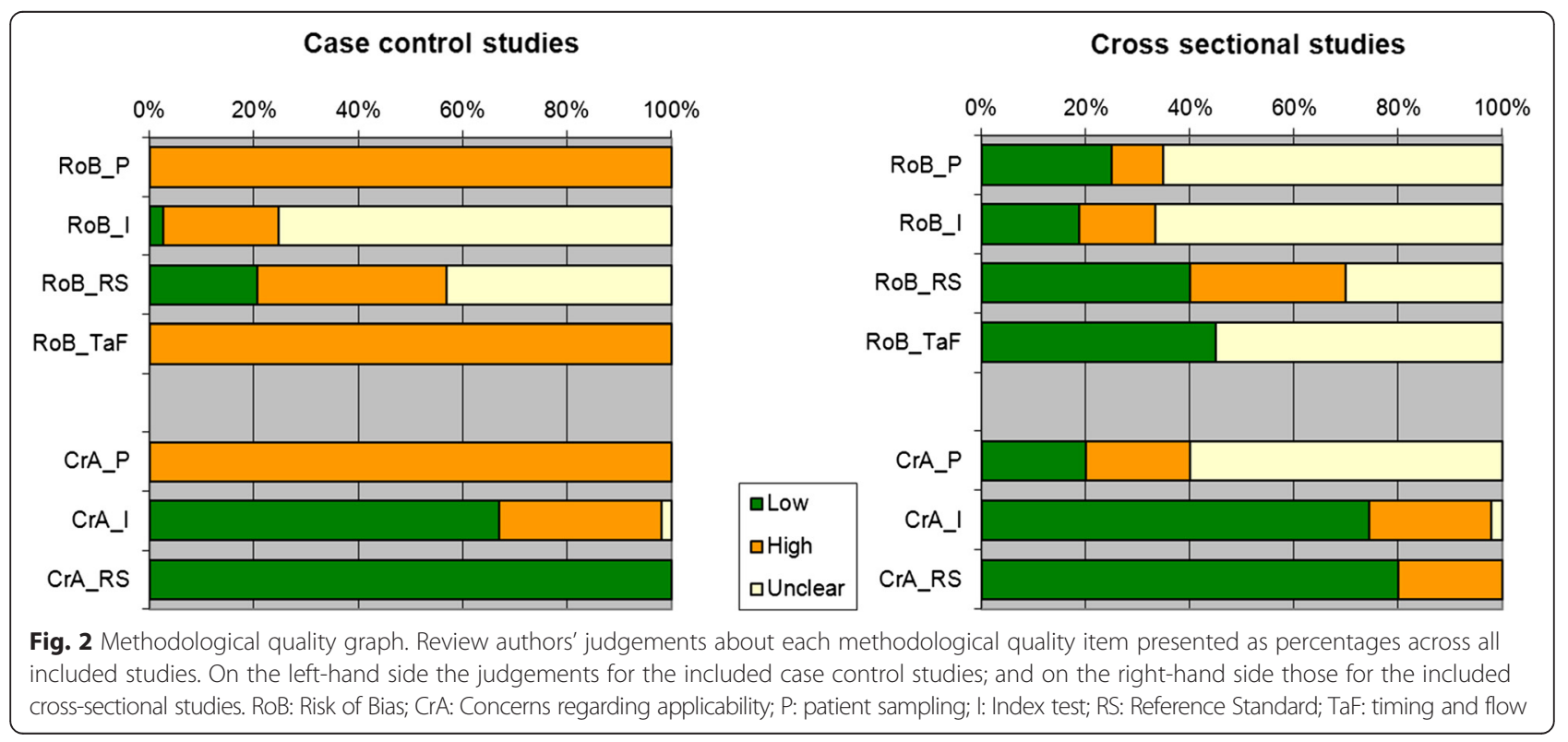


Table 1 Quality assessment of included case control studies

\begin{tabular}{|c|c|c|c|c|c|c|c|c|}
\hline Author Year & Design & RoB_P & CrA_P & RoB_I & CrA_I & RoB_RS & CrA_RS & RoB_TaF \\
\hline Ang 2011 & Case control & High & High & Unclear & Low & Unclear & Low & High \\
\hline Ang 2012 & Case control & High & High & Unclear & Low & Unclear & Low & High \\
\hline Bergstrom 1991 & Case control & High & High & High & High & High & Low & High \\
\hline Branda 2013 & Case control & High & High & Unclear & Low & High & Low & High \\
\hline Cerar 2006 & Case control & High & High & Unclear & Low & Low & Low & High \\
\hline Cerar 2010 & Case control & High & High & Unclear & Low & Unclear & Low & High \\
\hline Christova 2003 & Case control & High & High & Unclear & Low & Unclear & Low & High \\
\hline Cinco 2006 & Case control & High & High & Unclear & Low & Unclear & Low & High \\
\hline Dessau 2010 & Case control & High & High & Unclear & Low & High & Low & High \\
\hline Dessau 2013 & Case control & High & High & Unclear & Low & High & Low & High \\
\hline Flisiak 1996 & Case control & High & High & Unclear & Low & Low & Low & High \\
\hline Flisiak 1998 & Case control & High & High & Unclear & Low & Low & Low & High \\
\hline Goettner 2005 & Case control & High & High & Unclear & High & High & Low & High \\
\hline Goossens 2000 & Case control & High & High & Unclear & Low & Unclear & Low & High \\
\hline Goossens 2001 & Case control & High & High & Unclear & Low & Unclear & Low & High \\
\hline Gueglio 1996 & Case control & High & High & Unclear & Low & Unclear & Low & High \\
\hline Hansen 1988 & Case control & High & High & High & High & Unclear & Low & High \\
\hline Hansen 1989 & Case control & High & High & High & High & Low & Low & High \\
\hline Hansen 1991 & Case control & High & High & High & Low & Low & Low & High \\
\hline Hernandez 2003 & Case control & High & High & Unclear & Low & Unclear & Low & High \\
\hline Hofmann 1990 & Case control & High & High & Unclear & Low & Unclear & Low & High \\
\hline Hofmann 1996 & Case control & High & High & Unclear & Low & Unclear & Low & High \\
\hline Hofstad 1987 & Case control & High & High & High & High & Low & Low & High \\
\hline Hunfeld 2002 & Case control & High & High & Unclear & Low & Unclear & Low & High \\
\hline Jovivic 2003 & Case control & High & High & High/Unclear* & High & Unclear & Low & High \\
\hline Kaiser 1998 & Case control & High & High & High & High & High & Low & High \\
\hline Kaiser 1999inf & Case control & High & High & High & High & High & Low & High \\
\hline Karlsson 1989eur & Case control & High & High & High/Unclear* & High & Low & Low & High \\
\hline Karlsson 1989siid & Case control & High & High & High & High & Low & Low & High \\
\hline Lahdenne 2003 & Case control & High & High & High & Low & Unclear & Low & High \\
\hline Lakos 2005 & Case control & High & High & Low & High/Low* & High & Low & High \\
\hline Lange 1991 & Case control & High & High & Unclear & High/Low* & Unclear & Low & High \\
\hline Lencakova 2008 & Case control & High & High & Low/Unclear* & High/Low* & Unclear & Low & High \\
\hline Marangoni 2005jmm & Case control & High & High & Unclear & Low & Low & Low & High \\
\hline Marangoni 2005new & Case control & High & High & Unclear & Low $^{*}$ & Low & Low & High \\
\hline Marangoni 2008 & Case control & High & High & Unclear & Unclear** & Unclear & Low & High \\
\hline Mathiesen 1996 & Case control & High & High & High/Low* & High/Low* & High & Low & High \\
\hline Mathiesen 1998 & Case control & High & High & High/Unclear* & High/Low* & Low & Low & High \\
\hline Nicolini 1992 & Case control & High & High & High & High & Unclear & Low & High \\
\hline Nohlmans 1994 & Case control & High & High & High/Unclear* & High/Low* & Unclear & Low & High \\
\hline Oksi 1995 & Case control & High & High & High/Unclear* & High/Low* & Unclear & Low & High \\
\hline Olsson 1991 & Case control & High & High & High & High & Unclear & Low & High \\
\hline Panelius 2001 & Case control & High & High & High & High & High & Low & High \\
\hline Putzker 1995 & Case control & High & High & Unclear & Low & High & Low & High \\
\hline
\end{tabular}


Table 1 Quality assessment of included case control studies (Continued)

\begin{tabular}{|c|c|c|c|c|c|c|c|c|}
\hline Rauer 1995 & Case control & High & High & High & High & High & Low & High \\
\hline Reiber 2013 & Case control & High & High & High & Unclear & Low & Low & High \\
\hline Rijpkema 1994 & Case control & High & High & Unclear & High/Low* & Unclear & Low & High \\
\hline Ruzic 2002 & Case control & High & High & Unclear & Low & Unclear & Low & High \\
\hline Ryffel 1998 & Case control & High & High & Unclear & High & High & Low & High \\
\hline Schulte 2004 & Case control & High & High & Unclear & High & High & Low & High \\
\hline Smismans 2006 & Case control & High & High & Unclear & Low & High & Low & High \\
\hline Tjernberg 2007 & Case control & High & High & Unclear & Low/Unclear* & High & Low & High \\
\hline Tjernberg 2011 & Case control & High & High & Unclear & Low & High & Low & High \\
\hline VanBurgel 2011 & Case control & High & High & Unclear & Low & High & Low & High \\
\hline Wilske 1993 & Case control & High & High & High/Unclear* & High/Low* & High & Low & High \\
\hline Wilske 1999 & Case control & High & High & Unclear & High & High & Low & High \\
\hline Zoller 1990 & Case control & High & High & Unclear & High & Unclear & Low & High \\
\hline
\end{tabular}

RoB_P: Risk of Bias in patient sampling; RoB_l: Risk of Bias in Index test; RoB_RS: Risk of Bias in Reference Standard; RoB_TaF: Risk of Bias in timing and flow. CrA_P: Concerns regarding applicability of patient sample; CrA_I: Concerns regarding applicability of Index Test; CrA_RS: Concerns regarding applicability of Reference Standard. * some studies evaluated more than one test and evaluated these in different ways (e.g. for one test the cut-off value was pre-specified, while for the other test it was based on the results)

for neuroborreliosis had a median prevalence of $50 \%$ (IQR $37 \%$ to $70 \%$ ). The summary sensitivity for any serological test done in serum was $78 \%(95 \%$ CI $53 \%$ to $92 \%)$ and specificity was $78 \%$ (95\% CI $40 \%$ to $95 \%$ ) (Fig. 3b). Whether a test was ELISA or immunoblot, commercial or in-house did not affect model parameters.

\section{Lyme Arthritis}

Meta-analysis was not possible for the eight case-control studies on Lyme arthritis with healthy controls. We therefore only report the median estimates and their interquartile range (IQR). Median sensitivity was $96 \%$ (IQR $93 \%$ to $100 \%$ ); median specificity was $94 \%$ (IQR

Table 2 Quality assessment of included cross-sectional control studies

\begin{tabular}{|c|c|c|c|c|c|c|c|c|}
\hline Author_Year & Design & RoB_P & CrA_P & RoB_I & CrA_I & RoB_RS & CrA_RS & RoB_TaF \\
\hline Albisetti 1997 & Cross sectional & Low & Low & Unclear & Low & Low & Low & Unclear \\
\hline Barrial 2011 & Cross sectional & Unclear & Unclear & Low & Low & Low & Low & Low \\
\hline Bazovska 2001 & Cross sectional & Unclear & Unclear & Unclear & Low & Unclear & Low & Low \\
\hline Bednarova 2006 & Cross sectional & Unclear & Unclear & Unclear & Low & Unclear & Low & Unclear \\
\hline Bennet 2008 & Cross sectional & Unclear & High & Unclear & Low & Unclear & Low & Unclear \\
\hline Blaauw 1993 & Cross sectional & Low & Low & High & High & Low & Low & Low \\
\hline Blaauw 1999 & Cross sectional & Low & High & Unclear & High/Low* & Low & Low & Unclear \\
\hline Blanc 2007 & Cross sectional & Unclear & Unclear & Unclear & Low & High & Low & Unclear \\
\hline Cermakova 2005 & Cross sectional & Low & Low & Unclear & Low & High & Low & Low \\
\hline Davidson 1999 & Cross sectional & Unclear & Unclear & Unclear & High/Low* & High & High & Low \\
\hline Ekerfelt 2004 & Cross sectional & Unclear & Unclear & Low & Low & Unclear & Low & Unclear \\
\hline Jansson 2005 & Cross sectional & Unclear & Unclear & Unclear & Low & High & High & Low \\
\hline Kolmel 1992 & Cross sectional & Unclear & Unclear & Unclear & Low & High & Low & Unclear \\
\hline Ljostad 2005 & Cross sectional & High & High & Unclear & Unclear & Low & Low & Low \\
\hline Popperl 2000 & Cross sectional & Unclear & Unclear & Unclear & Low & High & High & Low \\
\hline Roux 2007 & Cross sectional & High & Unclear & Unclear & High/Low* & Low & High & Unclear \\
\hline Skarpaas 2007 & Cross sectional & Low & Low & High/Unclear* & Low & Unclear & Low & Unclear \\
\hline Skogman 2008 & Cross sectional & Unclear & Unclear & High & High & Low & Low & Low \\
\hline
\end{tabular}

RoB_P: Risk of Bias in patient sampling; RoB_l: Risk of Bias in Index test; RoB_RS: Risk of Bias in Reference Standard; RoB_TaF: Risk of Bias in timing and flow. CrA_P: Concerns regarding applicability of patient sample; CrA_l: Concerns regarding applicability of Index Test; CrA_RS: Concerns regarding applicability of Reference Standard. * some studies evaluated more than one test and evaluated these in different ways (e.g. for one test the cut-off value was pre-specified, while for the other test it was based on the results) 
Table 3 Summary estimates of sensitivity and specificity for all case-definitions, derived from a hierarchical summary ROC model. The results may be different from those in the main text, as here they are specified for immunoblots and ELISAs and for commercial and in-house tests separately, while in the main text the overall estimates are provided

\begin{tabular}{|c|c|c|c|c|c|c|c|}
\hline Case definition & Assay & Design & $\begin{array}{l}\mathrm{N} \text { (studies); N(2×2 } \\
\text { tables); N(cases); } \\
\mathrm{N}(\text { controls) }\end{array}$ & Sensitivity $(95 \%$ Cl) & Specificity (95 \% Cl) & Heterogeneity & Quality and Study Design \\
\hline \multirow{5}{*}{$\begin{array}{l}\text { Erythema } \\
\text { migrans }\end{array}$} & In-house ELISA & \multirow{5}{*}{$\begin{array}{l}\text { Case-control, } \\
\text { Healthy controls }\end{array}$} & $6,10,451,658$ & $0.41(0.25$ to 0.60$)$ & $0.97(0.95$ to 0.98$)$ & \multirow{5}{*}{$\begin{array}{l}\text { IgG lower sensitivity than IgM. } \\
\text { Other sources of heterogeneity } \\
\text { were not found. }\end{array}$} & \multirow{5}{*}{$\begin{array}{l}\text { Study quality did not } \\
\text { influence the accuracy }\end{array}$} \\
\hline & In-house IB & & $3,3,182,380$ & $0.52(0.38$ to 0.65$)$ & $0.98(0.94$ to 0.99$)$ & & \\
\hline & $\begin{array}{l}\text { Commercial } \\
\text { ELISA }\end{array}$ & & $13,32,874,2509$ & $0.54(0.44$ to 0.65$)$ & $0.93(0.90$ to 0.95$)$ & & \\
\hline & Commercial IB & & $3,5,161,289$ & $0.58(0.49$ to 0.67$)$ & $0.86(0.75$ to 0.93$)$ & & \\
\hline & Two-tiered tests & & $2,7,125,190$ & range 0.12 to 0.64 & range 0.67 to 0.96 & & \\
\hline $\begin{array}{l}\text { Lyme } \\
\text { neuroborreliosis }\end{array}$ & In-house ELISA & \multirow[t]{5}{*}{$\begin{array}{l}\text { Case-control, } \\
\text { Healthy controls }\end{array}$} & $6,9,277,649$ & $0.69(0.60$ to 0.76$)$ & $0.88(0.72$ to 0.97$)$ & \multirow{7}{*}{$\begin{array}{l}\text { IgM and IgG have similar sensitivity } \\
\text { and specificity, lgG has a higher } \\
\text { accuracy. Recombinant tests } \\
\text { perform best. More recent studies } \\
\text { perform better than earlier studies. }\end{array}$} & \multirow{9}{*}{$\begin{array}{l}\text { If serology was not part } \\
\text { of the reference standard, } \\
\text { then specificity was lower. }\end{array}$} \\
\hline \multirow[t]{4}{*}{ (serum) } & In-house IB & & $5,8,253,445$ & $0.69(0.57$ to 0.80$)$ & $0.93(0.86$ to 0.97$)$ & & \\
\hline & $\begin{array}{l}\text { Commercial } \\
\text { ELISA }\end{array}$ & & $11,28,484,2920$ & $0.81(0.70$ to 0.89$)$ & $0.94(0.91$ to 0.96$)$ & & \\
\hline & Commercial IB & & $2,4,33,286$ & $0.81(0.57$ to 0.94$)$ & $0.92(0.88$ to 0.95$)$ & & \\
\hline & Two-tiered tests & & $1,5,15,100$ & range 0.41 to 0.87 & range 0.88 to 0.94 & & \\
\hline (csf) & Any ELISA & \multirow{2}{*}{$\begin{array}{l}\text { Case-control, } \\
\text { Cross-reacting } \\
\text { controls }\end{array}$} & $6,9,385,261$ & $0.74(0.38$ to 0.93$)$ & $0.96(0.85$ to 0.99$)$ & & \\
\hline$($ serum + csf) & Specific Al test & & $7,10,458,380$ & $0.86(0.63$ to 0.95$)$ & $0.94(0.85$ to 0.97$)$ & & \\
\hline \multirow[t]{2}{*}{$\begin{array}{l}\text { Lyme } \\
\text { neuroborreliosis }\end{array}$} & $\begin{array}{l}\text { Any ELISA or IB } \\
\text { (in serum) }\end{array}$ & \multirow[t]{2}{*}{$\begin{array}{l}\text { Cross-sectional } \\
\text { study }\end{array}$} & $6,12,282,412$ & $0.78(0.53$ to 0.92$)$ & $0.78(0.40$ to 0.95$)$ & \multirow{2}{*}{$\begin{array}{l}\text { Sensitivity similar for } \lg G \text { and } \operatorname{lgM} \text {; } \\
\text { specifcity higher for lgG. No other } \\
\text { sources of heterogeneity. }\end{array}$} & \\
\hline & $\begin{array}{l}\text { Specific Al test } \\
\text { (in serum and } \\
\text { CSF) }\end{array}$ & & $4,4,102,118$ & $0.79(0.34$ to 0.97$)$ & $0.96(0.64$ to 1.00$)$ & & \\
\hline Lyme arthritis & All ELISA & $\begin{array}{l}\text { Case-control, } \\
\text { Healthy controls }\end{array}$ & $8,26,160,1112$ & $\begin{array}{l}\text { Median0.96Interquartile } \\
\text { range } 0.93 \text { to } 1.00\end{array}$ & $\begin{array}{l}\text { Median } \\
0.94 \text { Interquartile } \\
\text { range } 0.91 \text { to } 0.97\end{array}$ & $\begin{array}{l}\text { IgM a much lower sensitivity than lgG. } \\
\text { No other sources of heterogeneity. }\end{array}$ & $\begin{array}{l}\text { Study quality did not } \\
\text { influence the accuracy }\end{array}$ \\
\hline Acrodermatitis & All ELISA & $\begin{array}{l}\text { Case-control, } \\
\text { Healthy controls }\end{array}$ & $10,27,256,1415$ & $0.97(0.94$ to 0.99$)$ & $0.95(0.88$ to 0.98$)$ & $\begin{array}{l}\text { IgM a much lower sensitivity than lgG. } \\
\text { No other sources of heterogeneity. }\end{array}$ & $\begin{array}{l}\text { Study quality did not } \\
\text { influence the accuracy }\end{array}$ \\
\hline \multirow{4}{*}{$\begin{array}{l}\text { Lyme } \\
\text { borreliosis } \\
\text { (unspecified) }\end{array}$} & In-house ELISA & \multirow{4}{*}{$\begin{array}{l}\text { Case-control, } \\
\text { Healthy controls }\end{array}$} & $4,7,115,215$ & $0.85(0.71$ to 0.93$)$ & $0.98(0.93$ to 0.99$)$ & \multirow{4}{*}{$\begin{array}{l}\text { Tests assessing both IgM and lgG have } \\
\text { highest sensitivity; specificity not very } \\
\text { variable. Recombinant tests and more } \\
\text { recent studies perform worse. }\end{array}$} & \multirow{5}{*}{$\begin{array}{l}\text { If serology was not part } \\
\text { of the reference standard, } \\
\text { then accuracy was lower. }\end{array}$} \\
\hline & In-house IB & & $2,4,98,126$ & $0.63(0.33$ to 0.86$)$ & $0.97(0.93$ to 0.99$)$ & & \\
\hline & $\begin{array}{l}\text { Commercial } \\
\text { ELISA }\end{array}$ & & $10,43,658,815$ & $0.70(0.52$ to 0.83$)$ & 0.95 (0.89 to 0.98$)$ & & \\
\hline & Commercial IB & & $1,4,26,62$ & $0.29(0.07$ to 0.68$)$ & $0.96(0.90$ to 0.98$)$ & & \\
\hline $\begin{array}{l}\text { Lyme } \\
\text { borreliosis } \\
\text { (unspecified) }\end{array}$ & Any ELISA or IB & $\begin{array}{l}\text { Cross-sectional } \\
\text { study }\end{array}$ & $5,14,226,914$ & $0.77(0.48$ to 0.93$)$ & $0.77(0.46$ to 0.93$)$ & $\begin{array}{l}\text { IgM lowest sensitivity, but highest } \\
\text { specificity; no other sources investigated. }\end{array}$ & \\
\hline
\end{tabular}

Number of studies is for each combination of case definition and assay category. Thus the same study may appear more than once. ELISA Enzyme Immuno Assay, IB Immunoblot, AI Antibody Index, CS Cerebrospinal Fluid 

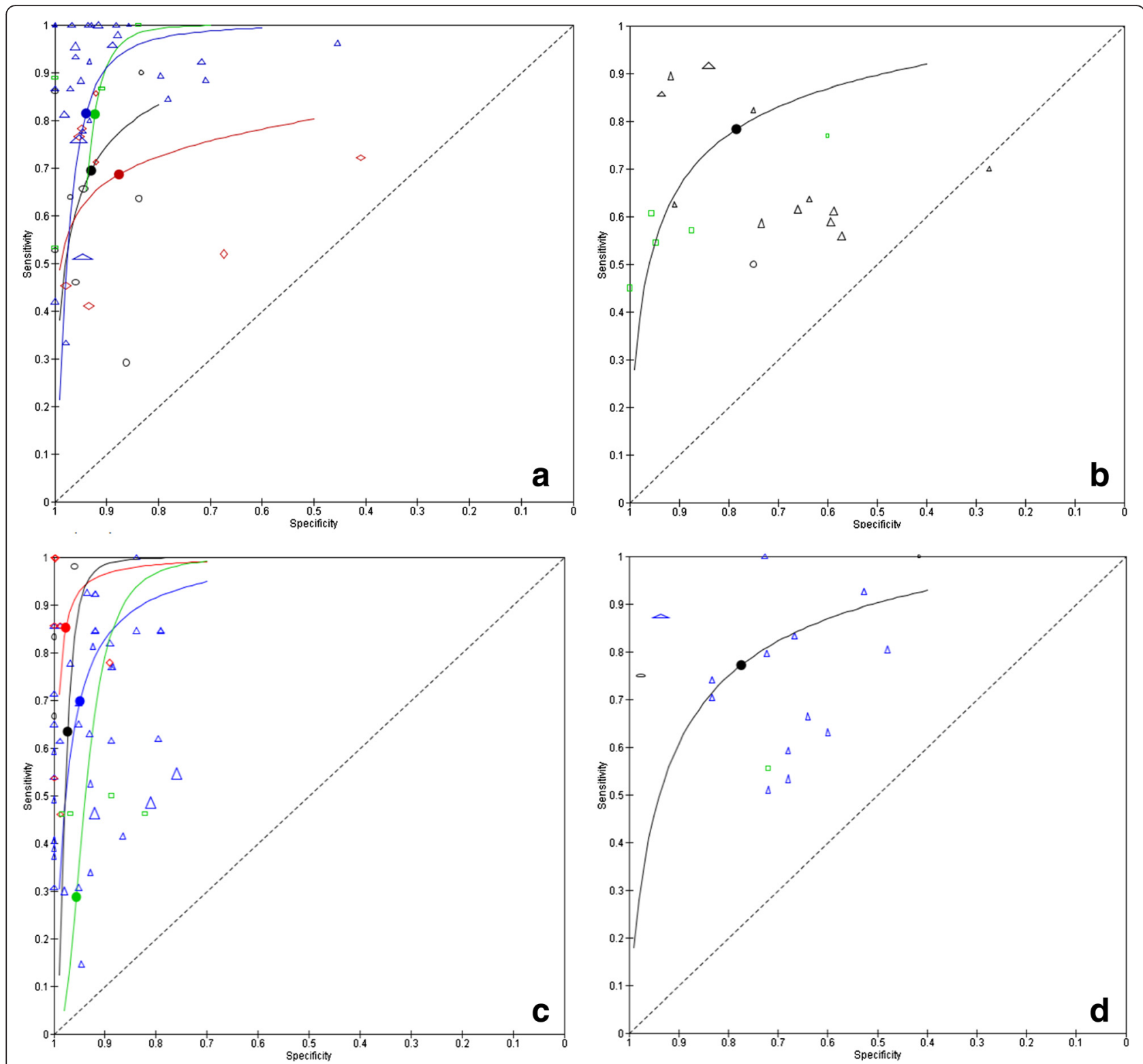

Fig. 3 Raw ROC plots and fitted summary ROC curves. Every symbol reflects a $2 \times 2$ table, one for each test. Blue triangle = commercial EIA; Red diamond $=$ in house EIA; Green rectangle = commercial IB; Black circle $=$ in house IB. One study may have contributed more than one $2 \times 2$ table. The dots on the summary ROC curves reflect the summary estimate of sensitivity and specificity. a neuroborreliosis case-control studies including healthy controls. b: neuroborreliosis cross-sectional studies. c unspecified Lyme borreliosis case-control studies including healthy controls. d unspecified Lyme borreliosis cross-sectional studies. The size of the symbol reflects the sample size. For the cross-sectional studies, only the overall summary ROC curve is shown, while for the case-control designs the curves are shown for the different test-types

$91 \%$ to $97 \%$ ) (Table 3). Three cross-sectional studies were done in patients suspected of Lyme arthritis; this was insufficient to do a meta-analysis $[66,71,85]$.

\section{Acrodermatitis chronica atrophicans}

The nine case control studies on ACA including a healthy control group had a high summary sensitivity for any serological assay: $98 \%$ (95\% CI $84 \%$ to $100 \%)$. Specificity was $94 \%$ (95\% CI $90 \%$ to $97 \%$ ). One study had an extremely low sensitivity for the in-house assay evaluated; most likely because one of the antigens used (OspC) is no longer expressed by the spirochetes in longstanding disease [45]. Test-type was not added to the analyses, because of insufficient data. Case-control studies for ACA including cross-reacting controls had a lower sensitivity and specificity than the healthy control designs (both $91 \%$ ).

\section{Unspecified Lyme borreliosis}

Thirteen case-control studies included unspecified Lyme borreliosis cases and healthy controls. Their summary 
sensitivity for any test was $73 \%$ (95\% CI $53 \%$ to 87 ) and specificity was $96 \%$ (95\% CI $91 \%$ to $99 \%$ ) (Fig. 3c). Commercial tests had a lower accuracy $(P$-value $=0 \cdot 008)$, mainly due to a lower sensitivity (Table 3 ). Twelve studies including cross-reacting controls had a summary sensitivity of $81 \%$ (95\% CI $64 \%$ to $91 \%$ ) and specificity of $90 \%$ (95\% CI $79 \%$ to $96 \%$ ). Five cross-sectional studies aimed to diagnose an unspecified form of Lyme borreliosis (Fig. 3d). The prevalence varied between 10 and $79 \%$, indicating a varying patient spectrum. Sensitivity was $77 \%$ (95\% CI $48 \%$ to $93 \%$ ) and specificity $77 \%$ (95\% CI $46 \%$ to $93 \%$ ). There were insufficient data points to analyze test type.

\section{Two-tiered tests}

One case-control study investigated the diagnostic accuracy of two-tiered approaches for all manifestations and healthy controls [11]. The sensitivity of the European algorithms varied between $55 \%$ for EM and $100 \%$ for ACA. The specificity for all assays was $\geq 99 \%$. Another casecontrol study investigated 12 different algorithms for 'late Lyme borreliosis' and 'early Lyme borreliosis' [21]. Their sensitivity varied between 4 and $50 \%$ and the specificity varied between 88 and $100 \%$. One case-control study including EM cases and healthy controls and evaluating two algorithms reported a sensitivity of $11 \%$ or $43 \%$ and a specificity of $100 \%$ [14]. Two cross-sectional studies on two-tiered tests aimed at diagnosing neuroborreliosis $[80,81]$ and two at diagnosing unspecified Lyme borreliosis $[67,70]$. Their prevalence varied between 19 and $77 \%$; their sensitivity between 46 and $97 \%$; and their specificity between 56 and $100 \%$.

\section{Specific antibody index}

Seven studies containing cross-reacting controls evaluated a specific antibody index for the diagnosis of neuroborreliosis. The summary sensitivity was $86 \%$ (95 \% CI $63 \%$ to
$95 \%$ ) and specificity $94 \%$ (95\% CI $85 \%$ to $97 \%$ ). The four cross-sectional studies had a summary sensitivity of $79 \%$ (95\% CI 34\% to $97 \%$ ) and a summary specificity of $96 \%$ (95\% CI $64 \%$ to $100 \%)$.

\section{Heterogeneity}

The IgG tests had a comparable sensitivity to the IgM tests, except for EM (IgM slightly higher sensitivity), Lyme arthritis and ACA (IgM much lower sensitivity in both). Tests assessing both IgM and IgG had the highest sensitivity and the lowest specificity, although specificity was above $80 \%$ in most cases. (Table 4 ).

We evaluated the effect of three antigen types: whole cell, purified proteins or recombinant antigens. In neuroborreliosis, recombinant antigens had both the highest sensitivity and specificity, while in unspecified Lyme, they had the lowest sensitivity and specificity. (Table 5) Year of publication showed an effect only for erythema migrans and neuroborreliosis: in both cases publications before the year 2000 showed a lower sensitivity than those after 2000. (Table 6) Antigen type and year of publication were not associated with each other.

For unspecified Lyme we were able to directly compare the accuracy in early stages of disease with the accuracy in later stages of disease. The tests showed a lower sensitivity and slightly higher specificity in the early stages of the disease. (Table 7).

We were able to meta-analyze manufacturer-specific results for only two manufacturers, but the results showed much variability and the confidence intervals were broad.

We investigated the effect of the reference standard domain of QUADAS-2: acceptable case definition versus no or unclear; and serology in the case definition versus no or unclear. None had a significant effect on accuracy. The study by Ang contained at least 8 different $2 \times 2$ tables for each case definition and may have therefore

Table 4 Summary estimates of sensitivity and specificity for IgM versus IgG versus IGM or IgG (IgT)

\begin{tabular}{|c|c|c|c|c|}
\hline & & $\lg M$ & $\lg G$ & $\lg T$ \\
\hline & & Estimate $(95 \% \mathrm{Cl})$ & Estimate $(95 \% \mathrm{Cl})$ & Estimate (95\% Cl) \\
\hline \multirow[t]{2}{*}{ Erythema migrans } & Sensitivity & 0.426 (0.361 to 0.494$)$ & 0.359 (0.293 to 0.431$)$ & 0.606 (0.503 to 0.700$)$ \\
\hline & Specifcitiy & $0.953(0.924$ to 0.971$)$ & 0.961 (0.939 to 0.975$)$ & 0.919 (0.885 to 0.944$)$ \\
\hline \multirow[t]{2}{*}{ Neuroborreliosis } & Sensitivity & $0.600(0.526$ to 0.669$)$ & 0.589 (0.515 to 0.659$)$ & $0.865(0.812$ to 0.906$)$ \\
\hline & Specifcitiy & 0.949 (0.924 to 0.966$)$ & 0.956 (0.935 to 0.971$)$ & 0.913 (0.869 to 0.942$)$ \\
\hline \multirow[t]{2}{*}{ Lyme arthritis } & Sensitivity & 0.392 (0.279 to 0.517$)$ & 0.941 (0.857 to 0.977 ) & $0.945(0.842$ to 0.982$)$ \\
\hline & Specifcitiy & 0.951 (0.881 to 0.980$)$ & 0.969 (0.942 to 0.983$)$ & 0.921 (0.837 to 0.964$)$ \\
\hline \multirow[t]{2}{*}{ Acrodermatitis Chronica Atrophicans } & Sensitivity & 0.184 (0.090 to 0.340$)$ & 0.987 (0.821 to 0.999$)$ & $0.978(0.874$ to 0.996$)$ \\
\hline & Specifcitiy & 0.965 (0.930 to 0.983$)$ & 0.966 (0.952 to 0.976$)$ & $0.932(0.883$ to 0.962$)$ \\
\hline \multirow[t]{2}{*}{ Unspecified Lyme borreliosis* } & Sensitivity & 0.596 (0.324 to 0.820$)$ & 0.557 (0.448 to 0.661$)$ & 0.792 (0.960 to 0.867$)$ \\
\hline & Specifcitiy & 0.911 (0.818 to 0.959$)$ & 0.986 (0.877 to 0.998$)$ & $0.947(0.725$ to 0.992$)$ \\
\hline
\end{tabular}

IgT refers to assays measuring lgM and IgG simultaneously. $95 \% \mathrm{Cl}=95 \%$ confidence interval. *Analyses were not possible for healthy controls; these are the estimates for studies including cross-reacting controls 
Table 5 Generation of antigens

\begin{tabular}{|c|c|c|c|}
\hline & Antigen & Sensitivity (95 \% Cl) & Specificity $(95 \% \mathrm{Cl})$ \\
\hline \multirow[t]{3}{*}{ Erythema migrans } & Whole cell & 0.515 (0.328 to 0.699$)$ & 0.957 (0.899 to 0.983$)$ \\
\hline & Purified & 0.579 (0.466 to 0.685$)$ & 0.950 (0.895 to 0.977$)$ \\
\hline & Recombinant & 0.551 (0.330 to 0.753 ) & 0.947 (0.881 to 0.977 ) \\
\hline \multirow[t]{3}{*}{ Neuroborreliosis } & Whole cell & 0.723 (0.555 to 0.845$)$ & 0.904 (0.792 to 0.959$)$ \\
\hline & Purified & 0.756 (0.614 to 0.858 ) & 0.963 (0.935 to 0.979$)$ \\
\hline & Recombinant & 0.837 (0.647 to 0.935$)$ & 0.931 (0.881 to 0.960$)$ \\
\hline \multirow[t]{2}{*}{ Lyme arthritis* } & Whole cell or Purified & 0.952 (0.892 to 0.979 ) & 0.958 (0.879 to 0.986$)$ \\
\hline & Recombinant & 0.954 (0.862 to 0.985$)$ & 0.927 (0.886 to 0.954$)$ \\
\hline \multirow[t]{3}{*}{ Unspecified Lyme borreliosis } & Whole cell & 0.703 (0.563 to 0.813 ) & 0.950 (0.863 to 0.983$)$ \\
\hline & Purified & 0.836 (0.463 to 0.968$)$ & 0.965 (0.855 to 0.992$)$ \\
\hline & Recombinant & 0.464 (0.251 to 0.692$)$ & 0.918 (0.806 to 0.968$)$ \\
\hline
\end{tabular}

For ACA there were insufficient data to analyse the effect of antigen used, so ACA is not in the table. $95 \% \mathrm{Cl}=95 \%$ confidence interval. *Insufficient data to analyse whole cell assays and purified antigen assays separately

weighed heavily on the results [8]. However, sensitivity analysis showed that its effect was only marginal. The same was true for assuming possible cases as being controls and indeterminate test results as being negatives.

\section{Discussion}

Overall, the diagnostic accuracy of ELISAs and immunoblots for Lyme borreliosis in Europe varies widely, with an average sensitivity of $\sim 80 \%$ and a specificity of $\sim 95 \%$. For Lyme arthritis and ACA the sensitivity was around $95 \%$. For EM the sensitivity was $\sim 50 \%$. In cross-sectional studies of neuroborreliosis and unspecified Lyme borreliosis, the sensitivity was comparable to the case-control designs, but the specificity decreased to 78 and $77 \%$ respectively. Two-tiered tests did not outperform single tests. Specific antibody index tests did not outperform the other tests for neuroborreliosis, although the specificity remained high even in the cross-sectional designs. All results should be interpreted with caution, as the results showed much variation and the included studies were at high risk of bias.

Although predictive values could not be meta-analyzed, the sensitivity and specificity estimates from this review may be used to provide an idea of the consequences of testing when the test is being used in practice. Imagine that a clinician sees about 1000 people a year who are suspected of one of the manifestations of Lyme borreliosis, in a setting where the expected prevalence of that manifestation is
$10 \%$. A prevalence of $10 \%$ would mean that 100 out of 1000 tested patients will really have a form of Lyme borreliosis. If these people are tested by an ELISA with a sensitivity $80 \%$, then $0.80 * 100=80$ patients with Lyme borreliosis will test positive and 20 patients will test negative. If we assume a specificity of $80 \%$ as well (following the estimates from the cross-sectional designs), then out of the 900 patients without Lyme borreliosis, $0.80 * 900=720$ will test negative and 180 will test positive. These numbers mean that in this hypothetical cohort of 1000 tested patients, 80 $+180=260$ patients will have a positive test result. Only 80 of these will be true positives and indeed have Lyme borreliosis (positive predictive value $80 / 260=0.31=31 \%$ ). The other 180 positively tested patients are the false positives and they will be treated for Lyme while they have another cause of disease, thus delaying their final diagnosis and subsequent treatment. In a two-tiered approach, all positives will be tested with immunoblot after ELISA. These numbers also mean that we will have $720+20=740$ negative test results, of which $3 \%$ (negative predictive value 720 / $740=0.97=97 \%$ ) will have Lyme borreliosis despite a negative test result. These are the false-negatives, their diagnosis will be missed or delayed. Although calculations like these may provide insight in the consequences of testing, they should be taken with caution. The results were overall very heterogeneous and may depend on patient characteristics. Also, the prevalence of $10 \%$ may not be realistic. In

Table 6 Year of publication

\begin{tabular}{llll}
\hline & Year of publication & Sensitivity $(95 \% \mathrm{Cl})$ & Specificity (95 \% Cl) \\
\hline Erythema migrans & $<2000$ & $0.631(0.515$ to 0.733$)$ & $0.897(0.818$ to 0.944$)$ \\
Neuroborreliosis & 2000 or later & $0.853(0.724$ to 0.928$)$ & 0.929 (0.826 to 0.973$)$ \\
& $<2000$ & $0.631(0.515$ to 0.733$)$ & $0.897(0.818$ to 0.944$)$ \\
& 2000 or later & $0.853(0.724$ to 0.928$)$ & 0.929 (0.826 to 0.973$)$ \\
\hline
\end{tabular}


Table 7 Early versus late Lyme borreliosis

\begin{tabular}{lllll}
\hline & & Overall & Early Lyme & Late Lyme \\
& & Estimate $(95 \% \mathrm{Cl})$ & Estimate $(95 \% \mathrm{Cl})$ & Estimate $(95 \%$ Cl) \\
\hline Unspecified Lyme borreliosis & Sensitivity & $0.774(0.468$ to 0.930$)$ & $0.600(0.323$ to 0.826$)$ & $0.798(0.554$ to 0.926$)$ \\
& Specifcitiy & $0.960(0.852$ to 0.990$)$ & $0.968(0.904$ to 0.990$)$ & $0.957(0.875$ to 0.986$)$ \\
\hline
\end{tabular}

$95 \% \mathrm{Cl}=95 \%$ confidence interval

our review, we found prevalences ranging from 1 to $79 \%$ for unspecified Lyme borreliosis and ranging from 12 to $62 \%$ for neuroborreliosis. Appendix 3 shows some more of these inferences, for different prevalence situations and different sensitivity and specificity of the tests.

Limitations of this review are the representativeness of the results, the poor reporting of study characteristics and the lack of a true gold standard. Most studies included were case-control studies. These may be easier to perform in a laboratory setting than cross-sectional designs, but their results are less representative for clinical practice. Also the immunoblot was not analysed in a way that is representative for practice: most immunoblots were analysed on the same samples as the ELISAs, while in practice immunoblots will only be used on ELISA-positive samples. EM patients formed the second largest group of patients in our review. The low sensitivity in this group of patients supports the guidelines stating that serological testing in EM patients is not recommended [86]. On the other hand, patients with atypical manifestations were not included in the reviewed studies, while this group of patients does form a diagnostic problem [87, 88]. A more detailed analyses of the included patients' characteristics and test characteristics would have been nice, but these characteristics were poorly reported. This is also reflected in the Quality-assessment table, with many 'unclear' scores, even for more recent studies. Authors may not have been aware of existing reporting guidelines and we therefore suggest that authors of future studies use the STAndards for Reporting Diagnostic accuracy studies (STARD) to guide their manuscript [89].

There is no gold standard for Lyme borreliosis, so we used the reference standard as presented by the authors of the included studies. This may have added to the amount of variation. Furthermore, many of the investigated studies included the results from antibody testing in their definition of Lyme borreliosis, which may have overestimated sensitivity and specificity. However, this was not proven in our heterogeneity analyses.

The performance of diagnostic tests very much depends on the population in which the test is being used. Future studies should therefore be prospective cross-sectional studies including a consecutive sample of presenting patients, preferably stratified by the situation in which the patient presents (e.g. a tertiary Lyme referral center versus general practice). The lack of a gold standard may be solved by using a reference standard with multiple levels of certainty [90,91]. Although this will diminish contrasts and will thus be more difficult to interpret, it does reflect practice in a better way. Other solutions may be more statistically derived approaches like latent class analysis, use of expert-opinion and/or response to treatment [92].

However, more and better designed diagnostic accuracy studies will not improve the accuracy of these tests themselves. They will provide more valid estimates of the tests' accuracy, including predictive values, but the actual added value of testing for Lyme disease requires information about subsequent actions and consequences of testing. If the final diagnosis or referral pattern is solely based upon the clinical picture, then testing patients for Lyme may have no added value. In that case, a perfect test may still be useless if it does not change clinical management decisions [93]. On the other hand, imperfect laboratory tests may still be valuable for clinical decision making if subsequent actions improve the patient's outcomes. The challenge for clinicians is to deal with the uncertainties of imperfect laboratory tests.

\section{Conclusions}

We found no evidence that ELISAs have a higher or lower accuracy than immunoblots; neither did we find evidence that two-tiered approaches have a better performance than single tests. However, the data in this review do not provide sufficient evidence to make inferences about the value of the tests for clinical practice. Valid estimates of sensitivity and specificity for the tests as used in practice require well-designed cross-sectional studies, done in the relevant clinical patient populations. Furthermore, information is needed about the prevalence of Lyme borreliosis among those tested for it and the clinical consequences of a negative or positive test result. The latter depend on the place of the test in the clinical pathway and the clinical decisions that are driven by the test results or not. Future research should primarily focus on more targeted clinical validations of these tests and research into appropriate use of these tests.

\section{Availability of data and materials}

The raw data (data-extraction results, reference lists, statistical codes) will be provided upon request by ECDC (info@ecdc.europa.eu). 


\section{Appendix 1}

Table 8 Search strategy

Search strategy in Ovidsp: database Embase 1980-present date search January 10, 2013; for the update in February 2014 we used the same strategy

\begin{tabular}{|c|c|}
\hline Line\# & Term \\
\hline 1 & exp serology/ \\
\hline 2 & serolog*.ti,ab,ot. \\
\hline 3 & antibod*.ti,ab,ot. \\
\hline 4 & exp antibody/ \\
\hline 5 & immunoglobin*.ti,ab,ot. \\
\hline 6 & lgG.ti,ab,ot. \\
\hline 7 & IgM.ti,ab,ot. \\
\hline 8 & exp enzyme linked immunosorbent assay/ \\
\hline 9 & ELISA.ti,ab,ot. \\
\hline 10 & exp immunoassay/ \\
\hline 11 & EIA.ti,ab,ot. \\
\hline 12 & immunosorbent.ti,ab,ot. \\
\hline 13 & immunofluorescent.ti,ab,ot. \\
\hline 14 & immunofluorescence.ti,ab,ot. \\
\hline 15 & immunoblot*.ti,ab,ot. \\
\hline 16 & "western blot".ti,ab,ot. \\
\hline 17 & immunoassay.ti,ab,ot. \\
\hline 18 & exp lymphocyte transformation test/ \\
\hline 19 & "Iymphocyte transformation test".ti,ab,ot. \\
\hline 20 & LTT.ti,ab,ot. \\
\hline 21 & $\begin{array}{l}\text { ((t-cell* or lymphocyte) adj15 (diagnostic or } \\
\text { diagnosis or diagnosing or screen* or test*)).mp. }\end{array}$ \\
\hline 22 & VIDAS.ti,ab,ot. \\
\hline 23 & liason.ti,ab,ot. \\
\hline 24 & Enzygnost.ti,ab,ot. \\
\hline 25 & Serion.ti,ab,ot. \\
\hline 26 & recomline.ti,ab,ot. \\
\hline 27 & (virotech adj5 (europline or "line blot")).ti,ab,ot. \\
\hline 28 & euroimmunoblot.ti,ab,ot. \\
\hline 29 & diacheck.ti,ab,ot. \\
\hline 30 & euroimmun.ti,ab,ot. \\
\hline 31 & Medac.ti,ab,ot. \\
\hline 32 & mikrogen\$̦.ti,ab,ot. \\
\hline 33 & virotech.ti,ab,ot. \\
\hline 34 & ELISPOT.ti,ab,ot. \\
\hline 35 & exp enzyme linked immunospot assay/ \\
\hline 36 & (c6 adj3 immunetics).ti,ab,ot. \\
\hline 37 & or/1-36 \\
\hline 38 & lyme.ti,ab,ot. \\
\hline 39 & Lyme borreliosis/ \\
\hline
\end{tabular}

Table 8 Search strategy (Continued)

\begin{tabular}{|c|c|c|}
\hline 40 & tick borne disease/ & 1803 \\
\hline 41 & exp tick bite/ & 1956 \\
\hline 42 & (tick adj2 bite).ti,ab,ot. & 1400 \\
\hline 43 & Neuroberreliosis.ti,ab,ot. & 0 \\
\hline 44 & exp erythema chronicum migrans/ & 1641 \\
\hline 45 & erythema migrans.ti,ab,ot. & 1187 \\
\hline 46 & "erythema chronicum migrans".ti,ab,ot. & 433 \\
\hline 47 & exp Acrodermatitis chronica atrophicans/ & 155 \\
\hline 48 & "Acrodermatitis chronica atrophicans".ti,ab,ot. & 426 \\
\hline 49 & meningoradiculitis.ti,ab,ot. & 269 \\
\hline 50 & lyme.ti,ab,ot. & 10067 \\
\hline 51 & Lyme borreliosis/ & 11571 \\
\hline 52 & tick borne disease/ & 1803 \\
\hline 53 & exp tick bite/ & 1956 \\
\hline 54 & (tick adj2 bite).ti,ab,ot. & 1400 \\
\hline 55 & Neuroborreliosis.ti,ab,ot. & 1091 \\
\hline 56 & exp erythema chronicum migrans/ & 1641 \\
\hline 57 & erythema migrans.ti,ab,ot. & 1187 \\
\hline 58 & "erythema chronicum migrans".ti,ab,ot. & 433 \\
\hline 59 & exp Acrodermatitis chronica atrophicans/ & 155 \\
\hline 60 & "Acrodermatitis chronica atrophicans".ti,ab,ot. & 426 \\
\hline 61 & meningoradiculitis.ti,ab,ot. & 269 \\
\hline 62 & lyme.ti,ab,ot. & 10067 \\
\hline 63 & Lyme borreliosis/ & 11571 \\
\hline 64 & tick borne disease/ & 1803 \\
\hline 65 & exp tick bite/ & 1956 \\
\hline 66 & (tick adj2 bite).ti,ab,ot. & 1400 \\
\hline 67 & exp erythema chronicum migrans/ & 1641 \\
\hline 68 & erythema migrans.ti,ab,ot. & 1187 \\
\hline 69 & "erythema chronicum migrans".ti,ab,ot. & 433 \\
\hline 70 & exp Acrodermatitis chronica atrophicans/ & 155 \\
\hline 71 & "Acrodermatitis chronica atrophicans".ti,ab,ot. & 426 \\
\hline 72 & meningoradiculitis.ti,ab,ot. & 269 \\
\hline 73 & Neuroborreliosis.ti,ab,ot. & 1091 \\
\hline 74 & or/38-73 & 16588 \\
\hline 75 & exp Borrelia/ & 10262 \\
\hline 76 & borrelia.ti,ab,ot. & 8824 \\
\hline 77 & burgdorferi.ti,ab,ot. & 7378 \\
\hline 78 & Borrelia infection/ & 2668 \\
\hline 79 & or/75-78 & 12748 \\
\hline 80 & VLsE.ti,ab,ot. & 142 \\
\hline 81 & OspC.ti,ab,ot. & 446 \\
\hline 82 & or/80-81 & 551 \\
\hline 83 & 74 or 79 & 20529 \\
\hline 84 & 82 or 83 & 20551 \\
\hline
\end{tabular}


Table 8 Search strategy (Continued)

\begin{tabular}{lll}
\hline 85 & 37 and 84 & 7578 \\
86 & 37 or 82 & 1630187 \\
87 & 83 and 86 & 7789 \\
88 & 85 or 87 & 7790 \\
89 & animal/not human/ & 1348171 \\
90 & 88 not 89 & 7369 \\
91 & review.pt. & 1907269 \\
92 & 90 not 91 & 6510 \\
\hline
\end{tabular}

\section{Appendix 2 Data quality \\ Patient selection \\ Risk of bias, signalling questions}

- Was a case-control design avoided?

o Case-control designs, especially if they include healthy controls, possess a high risk of bias. Therefore, all case-control studies are automatically judged to be of high risk of bias in the overall judgment.

- Was a consecutive or random sample of patients enrolled?

- Did the study avoid inappropriate exclusions?

- Overall judgment:

- Case-control studies always scored as high risk of bias

- Cross-sectional studies only low risk of bias if other two signalling questions are scored as 'yes'. If one of them is scored 'no', then high risk of bias. Otherwise unclear.

\section{Concerns regarding applicability}

This is about the extent to which the patients (both cases and controls) included in this study are representative for the patients in which these serology tests will be used.

- Is there concern that the included patients do not match the review question?

o All case-control studies automatically high concern. All cross-sectional studies automatically low concern, except when no clear casedefinition has been used.

- One study only included facial palsy patients $\rightarrow$ high concern: applicable, but not representative group

- One study only included arthritic patients $\rightarrow$ high concern: applicable, but not representative group

\section{Index test}

Risk of bias, signalling questions

- Were the index test results interpreted without knowledge of the results of the reference standard?
- If a threshold was used, was it pre-specified? By selecting the cut-off value with the highest sensitivity and/or specificity, researchers artificially optimize the accuracy of their tests, which also may cause overestimation of sensitivity and specificity.

$\circ$ The first question is very poorly reported, almost in all cases 'unclear'.

$\circ$ The second question varies. Sometimes the authors state that $95 \%$ value of the controls is used as threshold, or that the mean of the controls plus 2 or $3 \mathrm{SD}$ is used as threshold. Both variation have been scored as post-hoc.

- Overall judgment:

$\circ$ if the second question is scored as 'yes', then automatically overall judgement also scored as yes. This is because the first question will usually be not reported or scored as 'yes'.

- If the latter is scored as unclear, then overall also unclear; if latter is scored as no, then overall high risk.

\section{Concerns regarding applicability}

This is about the extent to which the index test evaluated is representative for the tests that will be used in practice.

- Is there concern that the index test, its conduct or interpretation differ from the review question?

$\circ$ All in-house tests automatically scored as high concern

Risk of bias and concerns regarding applicability should be scored for each test separately.

\section{Reference Standard}

Risk of bias, signalling questions

- Is the reference standard likely to correctly classify the target condition?

- Assumption: this will be likely in case-control studies that used the 'correct' case-definitions (e.g. Stanek [1], WHO)

- For cross-sectional studies also likely for studies that used the 'correct' case-definitions.

- Studies using Western blot as reference standard will be scored 'no' for this question.

- Were the reference standard results interpreted without knowledge of the results of the index test?

o Assumption: this will be likely in most casecontrol studies, but only if serology was not part of the case definition.

o For the cross-sectional studies, this should be explicitly stated.

- Overall judgement risk of bias: 
o case control studies with clear case-definitions scored with low risk of bias;

o case control studies with unclear/wrong casedefinitions score as unclear? Or high risk of bias?

- Cross-sectional studies with a clear casedefinition and the second question scored as 'yes': low risk of bias.

o Otherwise unclear, as latter question will be very poorly reported?

\section{Concerns regarding applicability}

Is there concern that the target condition as defined by the reference standard does not match the review question?

- Western blot measures antibody response, while we are interested in Lyme borreliosis, irrespective of antibody status. So western blots are considered to have high concerns regarding applicability.

- If serology included in case definition, then incorporation bias and thus high risk of bias.

- If a case-control study used clear criteria and did not include serology in these criteria, then Low concern.

\section{Risk of bias regarding flow and timing, signalling questions}

- Was there an appropriate interval between index test(s) and reference standard?

- We expected that in the cross-sectional designs most tests would have been done around the same moment as the final diagnosis was being made. If we suspect the patient status may have changed between the time of testing and the moment of diagnosis, then we scored this as 'no'.

- For case-control studies this was always scored as 'no', as the determination of serology was always done after the case-definitions were defined, sometimes a long time after that was done.

- Did patients receive the same reference standard?

o Were scored as 'no' for all case-control studies, as the controls were often from different settings, different departments and had to fulfil different criteria.

- Were all patients included in the analysis?

○ This was also scored 'no' for all case-control studies.

- Overall judgment:

- Case-control studies always scored high risk of bias o For cross-sectional studies, we scored low risk of bias if all three questions were scored 'yes' and high risk of bias if at least one of them was scored 'no'. All other cases were scored 'unclear'.

\section{Appendix 3 Possible ranges in post-test probability}

The Tables A to D show the absolute numbers of true positives, false positives, false negatives and true negatives for a hypothetical cohort of 1000 patients.

These numbers should be taken with caution, as the results were overall very heterogeneous. Furthermore, although the prevalence does not influence estimates of sensitivity and specificity extensively in our calculation, this assumption requires further elaboration.

To take into account variation in results and uncertainty, the calculations are made for different scenarios and presented in Tables A to D.

\begin{tabular}{|c|c|c|c|c|c|c|c|c|c|}
\hline \multicolumn{5}{|c|}{$\begin{array}{l}\text { TABLE A: specificity=95 \%, } \\
\text { prevalence }=10 \%\end{array}$} & \multicolumn{5}{|c|}{$\begin{array}{l}\text { TABLE B: specificity=80 \%, } \\
\text { prevalence }=10 \%\end{array}$} \\
\hline Sensitivity: & $\mathrm{TP}$ & FP & FN & $\mathrm{TN}$ & Sensitivity: & TP & $\mathrm{FP}$ & FN & $\mathrm{TN}$ \\
\hline 0.90 & 90 & 45 & 10 & 855 & 0.90 & 90 & 180 & 10 & 720 \\
\hline 0.85 & 85 & 45 & 15 & 855 & 0.85 & 85 & 180 & 15 & 720 \\
\hline 0.80 & 80 & 45 & 20 & 855 & 0.80 & 80 & 180 & 20 & 720 \\
\hline 0.75 & 75 & 45 & 25 & 855 & 0.75 & 75 & 180 & 25 & 720 \\
\hline 0.70 & 70 & 45 & 30 & 855 & 0.70 & 70 & 180 & 30 & 720 \\
\hline 0.60 & 60 & 45 & 40 & 855 & 0.60 & 60 & 180 & 40 & 720 \\
\hline 0.50 & 50 & 45 & 50 & 855 & 0.50 & 50 & 180 & 50 & 720 \\
\hline \multicolumn{5}{|c|}{$\begin{array}{l}\text { TABLE C: sensitivity=80 \%, } \\
\text { prevalence }=10 \%\end{array}$} & \multicolumn{5}{|c|}{$\begin{array}{l}\text { TABLE D: sensitivity=80 \%, } \\
\text { specificity=80 \%/95 \% }\end{array}$} \\
\hline Specificity: & $\mathrm{TP}$ & $\mathrm{FP}$ & FN & $\mathrm{TN}$ & Specificity: & 0.95 & & & \\
\hline 0.99 & 80 & 9 & 20 & 891 & Prevalence & $\mathrm{TP}$ & $\mathrm{FP}$ & FN & $\mathrm{TN}$ \\
\hline 0.95 & 80 & 45 & 20 & 855 & 0.05 & 40 & 48 & 10 & 903 \\
\hline 0.90 & 80 & 90 & 20 & 810 & 0.10 & 80 & 45 & 20 & 855 \\
\hline 0.85 & 80 & 135 & 20 & 765 & 0.20 & 160 & 40 & 40 & 760 \\
\hline 0.80 & 80 & 180 & 20 & 720 & Specificity: & 0.80 & & & \\
\hline 0.75 & 80 & 225 & 20 & 675 & Prevalence & TP & $\mathrm{FP}$ & $\mathrm{FN}$ & $\mathrm{TN}$ \\
\hline 0.70 & 80 & 270 & 20 & 630 & 0.05 & 40 & 190 & 10 & 760 \\
\hline 0.65 & 80 & 315 & 20 & 585 & 0.10 & 80 & 180 & 20 & 720 \\
\hline 0.60 & 80 & 360 & 20 & 540 & 0.20 & 160 & 160 & 40 & 640 \\
\hline
\end{tabular}

Table A: varying sensitivities, at a fixed specificity of $95 \%$ and a fixed prevalence of $10 \%$; Table B: varying sensitivities, at a more realistic fixed specificity of $80 \%$ and a fixed prevalence of $10 \%$; Table C: varying specificities, at a fixed sensitivity of $80 \%$ and a fixed prevalence of $10 \%$; Table D: sensitivity of $80 \%$ and a specificity of $80 \%$ and $95 \%$, at varying prevalence. 


\section{Abbreviations}

ACA: acrodermatitis chronica atrophicans; ELISA: enzyme-linked immunosorbent assays; EM: erythema migrans; HSROC: hierarchical summary ROC; Ig: immunoglobulin; QUADAS: QUAlity of Diagnostic Accuracy Studies; ROC: receiver operating characteristic.

\section{Competing interests}

All authors declare: HS and ML received financial support for the submitted work from ECDC; RD has received personal fees from Diarosin and Orian Diagnostica, personal fees and other from Siemens Diagnostica, other from Oxoid Thermofisher and Gilead, outside the submitted work; VF has received honoraria from DiaSorin, Mikrogen, Siemens and Virotech. $\mathrm{HZ}$ and WVB are employees of ECDC. All others report no support from any organisation for the submitted work; no financial relationships with any organisations that might have an interest in the submitted work in the previous three years; no other relationships or activities that could appear to have influenced the submitted work.

\section{Authors' contributions}

MMGL: study design, study inclusion, data collection, data analysis, drafted first version of manuscript, wrote subsequent versions of manuscript. ML acts as guarantor for the study. WA: data collection, data check, commented on draft versions of the manuscript, approved final version. JB: data collection, approved final version. HAB: coordinated author meetings and overall process, data collection, approved final version. WVB: study design, commented on draft versions of the manuscript, approved final version. $A B$ data collection, approved final version. NDvB: data collection, approved final version. APvD: data collection, data check, commented on draft versions of the manuscript, approved final version. RBD: data collection, data check, commented on draft versions of the manuscript, approved final version. VF: study design, approved final version. JWRH: data collection, data check, commented on draft versions of the manuscript, approved final version. BJ: study design, approved final version. BM: data collection, approved final version. WVP: data collection, commented on draft versions of the manuscript, approved final version. JFPS: data collection, commented on draft versions of the manuscript, approved final version. RS: literature retrieval, approved final version of manuscript. FFS: data collection, approved final version. GS: study design, approved final version. FV-L: data collection, approved final version. $\mathrm{HZ}$ : study design, approved final version. HS: coordination of overall process, study design, study inclusion, data collection, data check, commented on draft versions of manuscript, approved final version of manuscript. All authors read and approved the final manuscript.

\section{Acknowledgements}

We would like to thank our colleagues from the National Institute for Public Health and the Environment (Bilthoven) and Department of Clinical Epidemiology, Biostatistics and Bioinformatics, University of Amsterdam (Amsterdam) for critically reading this technical report. This project was funded by the European Centre for Disease Control and Prevention (ECDC). The funding source did not have any direct role in the study design, data collection, analysis or interpretation of data, except of funding the required resources. $\mathrm{HZ}$ and WVB are employees of ECDC but had no role in the dataextraction or study selection. All other authors are independent of ECDC.

\section{Author details}

${ }^{1}$ VU University Medical Center, PO Box 70571007 MB Amsterdam, The Netherlands. ${ }^{2}$ Canisius-Wilhelmina Hospital, PO Box 90156500 GS Nijmegen, The Netherlands. ${ }^{3}$ National Institute for Public Health and the Environment (RIVM), Antonie van Leeuwenhoeklaan 9, 3721 MA Bilthoven, The Netherlands. ${ }^{4}$ European Centre for Disease Prevention and Control (ECDC), 17183 Stockholm, Sweden. ${ }^{5}$ Izore Centre for Infectious Diseases Friesland, PO Box 210208900 JA Leeuwarden, The Netherlands. ${ }^{6}$ HagaZiekenhuis, Leyweg 275, $2545 \mathrm{CH}$ The Hague, Netherlands. ${ }^{7}$ Department of Medical Microbiology, Onze Lieve Vrouwe Gasthuis, P.O. Box 95500, 1090 HM Amsterdam, The Netherlands. ${ }^{8}$ Slagelse Hospital, Fælledvej 1, 4200 Slagelse, Region Zealand, Denmark. ${ }^{9}$ German National Reference Centre for Borrelia, Bavarian Health and Food Safety Authority, Veterinärstraße 2, 85764 Oberschleißheim, Germany. ${ }^{10}$ Centre for Experimental and Molecular Medicine, Academic Medical Center, Amsterdam, The Netherlands. ${ }^{11}$ National Reference Centre for Borrelia, Department Laboratory of Bacteriology, Strasbourg University Hospital, 1 Place de l'Hôpital, Strasbourg, France.
${ }^{12}$ Department of Clinical Epidemiology, Biostatistics and Bioinformatics, Academic Medical Center, University of Amsterdam, PO Box 22700, 1100 DE Amsterdam, The Netherlands. ${ }^{13}$ Laboratory for Infectious Diseases, PO Box 30039, 9700 RM Groningen, The Netherlands. ${ }^{14}$ Dutch Cochrane Centre, Julius Center for Health Sciences and Primary Care/University Medical Center, PO Box 855003508 GA Utrecht, The Netherlands. ${ }^{15}$ Radboud University Nijmegen Medical Centre, Geert Grooteplein-Zuid 10, 6525 GA Nijmegen, The Netherlands. ${ }^{16}$ Institute for Hygiene and Applied Immunology, Medical University of Vienna, Vienna, Austria. ${ }^{17}$ Department of Medical Microbiology University Medical Center Utrecht (UMC), P.O. Box 855003508GA Utrecht, The Netherlands.

Received: 29 September 2015 Accepted: 14 March 2016 Published online: 25 March 2016

\section{References}

1. Hubálek Z. Epidemiology of Lyme borreliosis. Curr Probl Dermatol. 2009;37: 31-50.

2. Stanek G, Wormser GP, Gray J, Strle F. Lyme borreliosis. Lancet. 2012;379: 461473.

3. Mulherin SA, Miller WC. Spectrum bias or spectrum effect? Subgroup variation in diagnostic test evaluation. Ann Intern Med. 2002;137:598602.

4. Knottnerus JA, Muris JW. Assessment of the accuracy of diagnostic tests: the cross-sectional study. J Clin Epidemiol. 2003;56:1118-28.

5. Rutjes AW, Reitsma JB, Vandenbroucke JP, Glas AS, Bossuyt PM. Case-control and two-gate designs in diagnostic accuracy studies. Clin Chem. 2005:51: 1335-41.

6. Whiting PF, Rutjes AW, Westwood ME, et al. QUADAS-2: a revised tool for the quality assessment of diagnostic accuracy studies. Ann Intern Med. 2011;155:529536.

7. Macaskill P, Gatsonis C, Deeks JJ, Harbord RM, Takwoingi Y. Chapter 10: Analysing and Presenting Results. In: Deeks JJ, Bossuyt PM, Gatsonis C, editors. Cochrane Handbook for Systematic Reviews of Diagnostic Test Accuracy Version 1.0. The Cochrane Collaboration, 2010. Available from: http://methods.cochrane.org/sdt/handbook-dta-reviews/.

8. Ang CW, Brandenburg AH, van Burgel ND, Bijlmer HA, Herremans T, Stelma FF, et al. Nationale vergelijking van serologische assays voor het aantonen van Borrelia-antistoffen. Nederlands tijdschrift voor Medische Microbiologie. 2012:20:111-9.

9. Ang CW, Notermans DW, Hommes M, Simoons-Smit AM, Herremans T. Large differences between test strategies for the detection of anti-Borrelia antibodies are revealed by comparing eight ELISAs and five immunoblots. Eur J Clin Microbiol Inf Dis. 2011;30:1027-32

10. Bergstrom S, Sjostedt A, Dotevall L, Kaijser B, Ekstrand-Hammarstrom B, Wallberg $C$, et al. Diagnosis of Lyme borreliosis by an enzyme immunoassay detecting immunoglobulin $\mathrm{G}$ reactive to purified Borrelia burgdorferi cell components. Eur J Clin Microbiol Inf Dis. 1991;10:422-7.

11. Branda JA, Strle F, Strle K, Sikand N, Ferraro MJ, Steere AC. Performance of United States serologic assays in the diagnosis of Lyme borreliosis acquired in Europe. Clin Infect Dis. 2013;57:333-40.

12. Cerar T, Ogrinc K, Strle F, Ruzic-Sabljic E. Humoral immune responses in patients with lyme neuroborreliosis. Clin Vaccine Immunol. 2010;17:645-50.

13. Cerar T, Ruzic-Sabljic E, Cimperman J, Strle F. Comparison of immunofluorescence assay (IFA) and LIAISON in patients with different clinical manifestations of Lyme borreliosis. Wien Klin Wochenschr. 2006;118:686-90.

14. Christova I. Enzyme-linked immunosorbent assay, immunofluorescent assay $X$ and recombinant immunoblotting in the serodiagnosis of early Lyme borreliosis. Int J Imm Pharmacol. 2003;16:261-8.

15. Cinco M, Murgia R. Evaluation of the C 6 enzyme-linked immunoadsorbent assay for the serodiagnosis of Lyme borreliosis in north-eastern Italy. New Microbiol. 2006;29:139-41.

16. Dessau RB, Ejlertsen T, Hilden J. Simultaneous use of serum IgG and IgM for risk scoring of suspected early Lyme borreliosis: Graphical and bivariate analyses. APMIS. 2010;118:313-23.

17. Dessau RB. Diagnostic accuracy and comparison of two assays for Borreliaspecific lgG and IgM antibodies: Proposals for statistical evaluation methods, cut-off values and standardization. J Med Microbiol. 2013;62(Pt 12):1835-44.

18. Flisiak R, Kalinowska A, Bobrowska E, Prokopowicz D. Enzyme immunoassay in the diagnosis of Lyme borreliosis. Roczniki Akademii Medycznej w Bialymstoku. 1996:41:83-9. 
19. Flisiak R, Wierzbicka I, Prokopowicz D. Western blot banding pattern in early Lyme borreliosis among patients from an endemic region of north-eastern Poland. Roczniki Akademii Medycznej w Bialymstoku. 1998;43:210-20.

20. Goettner G, Schulte-Spechtel U, Hillermann R, Liegl G, Wilske B, Fingerle V. Improvement of lyme borreliosis serodiagnosis by a newly developed recombinant immunoglobulin $\mathrm{G}(\mathrm{lgG})$ and IgM line immunoblot assay and addition of VlsE and DbpA homologues. J Clin Microbiol. 2005;43:3602-9.

21. Goossens HAT, van de Bogaard AE, Nohlmans MKE. Evaluation of fifteen commercially available serological tests for diagnosis of Lyme borreliosis. Eur J Clin Microbiol Inf Dis. 1999;18:551-60.

22. Goossens HAT, Van den Bogaard AE, Nohlmans MKE. Serodiagnosis of Lyme borreliosis using detection of different immunoglobulin (sub)classes by enzyme-linked immunosorbent assay and Western blotting. Clin Lab. 2001; 47:41-9.

23. Gueglio B, Poinsignon Y, Berthelot JM, Marjolet M. Borreliose De Lyme: Specificite De Western Blot. Med Mal Infect. 1996;26:332-7.

24. Hansen K, Asbrink E. Serodiagnosis of erythema migrans and acrodermatitis chronica atrophicans by the Borrelia burgdorferi flagellum enzyme-linked immunosorbent assay. J Clin Microbiol. 1989;27:545-51.

25. Hansen K, Hindersson P, Pedersen NS. Measurement of antibodies to the Borrelia burgdorferi flagellum improves serodiagnosis in Lyme borreliosis. J Clin Microbiol. 1988;26:338-46.

26. Hansen K, Lebech AM. Lyme neuroborreliosis: A new sensitive diagnostic assay for intrathecal synthesis of Borrelia burgdorferi-specific immunoglobulin G, A, and M. Ann Neurol. 1991;30:197-205.

27. Hernandez-Novoa B, Orduna A, Bratos MA, Eiros JM, Fernandez JM, Gutierrez MP, et al. Utility of a commercial immunoblot kit (BAG-Borrelia blot) in the diagnosis of the preliminary stages of Lyme borreliosis. Diagn Microbiol Inf Dis. 2003;47:321-9.

28. Hofmann H. Lyme borreliosis - Problems of serological diagnosis. Infection 1996;24:470-2.

29. Hofmann H, Meyer-Konig U. Serodiagnostik Bei Dermatologischen Krankheitsbildern Der Borrelia Burgdorferi-Infektion. Hautarzt. 1990;41:424-31.

30. Hofstad H, Matre R, Myland H, Ulvestad E. Bannwarth's syndrome: Serum and CSF IgG antibodies against Borrelia burgdorferi examined by ELISA. Acta Neurol Scand. 1987;75:37-45.

31. Hunfeld KP, Ernst M, Zachary P, Jaulhac B, Sonneborn HH, Brade V. Development and laboratory evaluation of a new recombinant ELISA for the serodiagnosis of Lyme borreliosis. Wien Klin Wochenschr. 2002;114:580-5.

32. Jovicic VL, Grego EM, Lako BL, Ristovic BM, Lepsanovic ZA, Stajkovic NT. Improved serodiagnosis of early Lyme borreliosis: Immunoblot with local Borrelia afzelli strain. APMIS. 2003;111:1053-9.

33. Kaiser R, Rauer $\mathrm{S}$. Analysis of the intrathecal immune response in neuroborreliosis to a sonicate antigen and three recombinant antigens of Borrelia burgdorferi sensu stricto. Eur J Clin Microbiol Inf Dis. 1998;17:159-66.

34. Kaiser R, Rauer S. Serodiagnosis of neuroborreliosis: Comparison of reliability of three confirmatory assays. Infection. 1999;27:177-82.

35. Karlsson M, Granstrom M. An IgM-antibody capture enzyme immunoassay for serodiagnosis of Lyme borreliosis. Serodiagn Immunother Infect Dis. 1989:3:413-21

36. Karlsson M, Mollegard I, Stiernstedt G, Wretlind B. Comparison of Western blot and enzyme-linked immunosorbent assay for diagnosis of Lyme borreliosis. Eur J Clin Microbiol Inf Dis. 1989;8:871-7.

37. Lahdenne P, Panelius J, Saxen H, Heikkila T, Sillanpaa H, Peltomaa M, et al. Improved serodiagnosis of erythema migrans using novel recombinant borrelial BBK32 antigens. J Med Microbiol. 2003;52:563-7.

38. Lakos A, Ferenczi E, Komoly S, Granström M. Different B-cell populations are responsible for the peripheral and intrathecal antibody production inneuroborreliosis. Int Immunol. 2005;17:1631-7.

39. Lange R, Schneider T, Topel U, Mater-Bohm H, Beck A, Kolmel HW. Borrelia burgdorferi antibody-tests: Comparison of IFT. ELISA Western-blot Lab Med. 1991;15:128-9.

40. Lencakova D, Fingerle V, Stefancikova A, Schulte-Spechtel U, Petko B, Schreter I, et al. Evaluation of recombinant line immunoblot for detection of Lyme borreliosis in Slovakia: Comparison with two other immunoassays. Vector-Borne Zoonot. 2008:8:381-90.

41. Marangoni A, Moroni A, Accardo S, Cevenini R. Borrelia burgdorferi VlsE antigen for the serological diagnosis of Lyme borreliosis. Eur J Clin Microbiol Inf Dis. 2008;27:349-54.

42. Marangoni A, Sparacino M, Cavrini F, Storni E, Mondardini V, Sambri V, et al. Comparative evaluation of three different ELISA methods for the diagnosis of early culture-confirmed Lyme borreliosis in Italy. J Med Microbiol. 2005;54:361-7.

43. Marangoni A, Sparacino M, Mondardini V, Cavrini F, Storni E, Donati M, et al. Comparative evaluation of two enzyme linked immunosorbent assay methods and three Western Blot methods for the diagnosis of cultureconfirmed early Lyme Borreliosis in Italy. New Microbiol. 2005;28:37-43.

44. Mathiesen MJ, Christiansen M, Hansen K, Holm A, Asbrink E, Theisen M. Peptide-based OspC enzyme-linked immunosorbent assay for serodiagnosis of Lyme borreliosis. J Clin Microbiol. 1998;36:3474-9.

45. Mathiesen MJ, Hansen K, Axelsen N, Halkier-Sorensen L, Theisen M. Analysis of the human antibody response to outer surface protein $\mathrm{C}(\mathrm{OspC})$ of Borrelia burgdorferi sensu stricto, B. garinii, and B. afzelii. Med Microbiol Immunol. 1996;185:121-9.

46. Nicolini $P$, Imbs P, Jaulhac B, Piemont $Y$, Warter JM, Monteil H. Comparaison De L'immunofluorescence Indirecte Et Du Western Blot Pour Le Serodiagnostic Des Infections Neurologiques a Borrelia Burgdorferi. Med Mal Inf. 1992;22:722-6.

47. Nohlmans MKE, Blaauw AAM, Van den Bogaard AEJ, Van Boven CPA. Evaluation of nine serological tests for diagnosis of Lyme borreliosis. Eur J Clin Microbiol Inf Dis. 1994;13:394-400.

48. Oksi J, Uksila J, Marjamaki M, Nikoskelainen J, Viljanen MK. Antibodies against whole sonicated Borrelia burgdorferi spirochetes, 41- kilodalton flagellin, and P39 protein in patients with PCR- or culture- proven late Lyme borreliosis. J Clin Microbiol. 1995;33:2260-4.

49. Olsson I, Von Stedingk LV, Hanson HS, Von Stedingk M, Asbrink E, Hovmark A. Comparison of four different serological methods for detection of antibodies to Borrelia burgdorferi in erythema migrans. Acta Derm-Venereol. 1991;71:127-33.

50. Panelius J, Lahdenne P, Saxen H, Heikkila T, Seppala I. Recombinant flagellin A proteins from Borrelia burgdorferi sensu stricto, B. afzelii, and B. garinii in serodiagnosis of Lyme borreliosis. J Clin Microbiol. 2001;39:4013-9.

51. Putzker M, Zoller L. Vergleichende Bewertung Kommerzieller Hamagglutinations-, Enzymimmun- Und Immunblottests in Der Serodiagnostik Der Lyane-Borreliose. Klinisches Labor. 1995:41:655-66.

52. Rauer S, Kayser M, Neubert U, Rasiah C, Vogt A. Establishment of enzyme-linked immunosorbent assay using purified recombinant 83-kilodalton antigen of Borrelia burgdorferi sensu stricto and Borrelia afzelii for serodiagnosis of Lyme borreliosis. J Clin Microbiol. 1995;33:2596-600.

53. Reiber H, Ressel CB, Spreer A. Diagnosis of neuroborreliosis - Improved knowledge base for qualified antibody analysis and cerebrospinal fluid data pattern related interpretations. Neurol Psych Brain Res. 2013;19:159-69.

54. Rijpkema S, Groen J, Molkenboer M, Herbrink P, Osterhaus A, Schellekens J. Serum antibodies to the flagellum of Borrelia burgdorferi measured with an inhibition enzyme-linked immunosorbent assay are diagnostic for Lyme borreliosis. Serodiagn Immunother Infect Dis. 1994;6:61-7.

55. Ruzic-Sabljic E, Maraspin V, Cimperman J, Lotric-Furian S, Strle F. Evaluation of immunofluorescence test (IFT) and immuno (western) blot (WB) test in patients with erythema migrans. Wien Klin Wochenschr. 2002;114:586-90.

56. Ryffel K, Peter $\mathrm{O}$, Binet $\mathrm{L}$, Dayer $\mathrm{E}$. Interpretation of immunoblots for Lyme borreliosis using a semiquantitative approach. Clin Microbiol Infect. 1998:4:205-12.

57. Schulte-Spechtel U, Lehnert G, Liegl G, Fingerle V, Heimerl C, Johnson B, et al. Significant improvement of the recombinant Borrelia lgG immunoblot for serodiagnosis of early neuroborreliosis. Int J Med Microbiol. 2004;293:158-60.

58. Smismans A, Goossens VJ, Nulens E, Bruggeman CA. Comparison of five different immunoassays for the detection of Borrelia burgdorferi lgm and IgG antibodies. Clin Microbiol Infect. 2006;12:648-55.

59. Tjernberg I, Henningsson AJ, Eliasson I, Forsberg P, Ernerudh J. Diagnostic performance of cerebrospinal fluid chemokine CXCL13 and antibodies to the C6-peptide in Lyme neuroborreliosis. J Infect. 2011;62:149-58.

60. Tjernberg I, Kruger G, Eliasson I. C6 peptide ELISA test in the serodiagnosis of Lyme borreliosis in Sweden. Eur J Clin Microbiol Infect Dis. 2007;26:37-42.

61. van Burgel ND, Brandenburg A, Gerritsen HJ, Kroes ACM, van Dam AP. High sensitivity and specificity of the C6-peptide ELISA on cerebrospinal fluid in Lyme neuroborreliosis patients. Clin Microbiol Infect. 2011;17:1495-500.

62. Wilske B, Fingerle $V$, Herzer $P$, Hofmann A, Lehnert $G$, Peters $H$, et al. Recombinant immunoblot in the serodiagnosis of Lyme borreliosis. Comparison with indirect immunofluorescence and enzyme-linked immunosorbent assay. Med Microbiol Immunol. 1993;182:255-70.

63. Wilske B, Habermann C, Fingerle V, Hillenbrand B, Jauris-Heipke S, Lehnert G, et al. An improved recombinant lgG immunoblot for serodiagnosis of Lyme borreliosis. Med Microbiol Immunol. 1999;188:139-44. 
64. Zoller L, Haude M, Sonntag HG. Validity of the standard assays in the serodiagnosis of Lyme borreliosis and effects of methodical modifications. Lab Med. 1990;14:404-11.

65. Albisetti M, Schaer G, Good M, Boltshauser E, Nadal D. Diagnostic value of cerebrospinal fluid examination in children with peripheral facial palsy and suspected Lyme borreliosis. Neurology. 1997:49:817-24.

66. Barrial K, Roure-Sobas C, Carricajo A, Boibieux A, Tigaud S. Evaluation des performances de quatre immunoblots commercialises pour la confirmation de la borreliose de Lyme dans une population de patients suivis en Rhone-Alpes. Immuno-Analyse et Biologie Specialisee. 2011;26:194-200

67. Bazovska S, Kondas M, Simkovicova M, Kmety E, Traubner P. Significance of specific antibody determination in Lyme borreliosis diagnosis. Bratisl Lek Listy. 2001;102:454-7.

68. Bednarova J. Cerebrospinal-fluid profile in neuroborreliosis and its diagnostic significance. Folia Microbiol. 2006;51:599-603.

69. Bennet R, Lindgren V, Zweygberg Wirgart B. Borrelia antibodies in children evaluated for Lyme neuroborreliosis. Infection. 2008;36:463-6.

70. Blaauw AAM, Van Loon AM, Schellekens JFP, Bijlsma JWJ. Clinical evaluation of guidelines and two-test approach for Lyme borreliosis. Rheumatology. 1999;38:1121-6.

71. Blaauw I, Dijkmans B, Bouma P, Van Der Linden S. Rational diagnosis and treatment in unclassified arthritis: How clinical data may guide requests for Lyme serology and antibiotic treatment. Ann Rheum Dis. 1993;52:206-10.

72. Blanc F, Jaulhac B, Fleury M, De Seze J, De Martino SJ, Remy V, et al. Relevance of the antibody index to diagnose Lyme neuroborreliosis among seropositive patients. Neurology. 2007;69:953-8.

73. Cermakova Z, Ryskova O, Honegr K, Cermakova E, Hanovcova I. Diagnosis of Lyme borreliosis using enzyme immunoanalysis. Med Sci Monitor. 2005;11: BR121-BR5.

74. Davidson MM, Ling CL, Chisholm SM, Wiseman AD, Joss AWL, Ho-Yen DO. Evidence-based diagnosis of Lyme borreliosis. Eur J Clin Microbiol Infect Dis. 1999;18:484-9.

75. Ekerfelt C, Ernerudh J, Forsberg P, Jonsson AL, Vrethem M, Arlehag L, et al. Lyme borreliosis in Sweden - Diagnostic performance of five commercial Borrelia serology kits using sera from well-defined patient groups. APMIS. 2004;112:74-8

76. Jansson C, Carlsson SA, Granlund H, Wahlberg P, Nyman D. Analysis of Borrelia burgdorferi IgG antibodies with a combination of IgG ELISA and VIsE C6 peptide ELISA. Clin Microbiol Infect. 2005;11:147-50.

77. Kolmel HW, Neumann P, Lange R. Korrelation Zwischen Neurologischer Erkrankung Und Borrelia-Burgdorferi-Antikorpern in 800 Serum/ Liquorpaaren. Nervenarzt. 1992;63:619-24.

78. Ljostad U, Okstad S, Topstad T, Mygland A, Monstad P. Acute peripheral facial palsy in adults. J Neurol. 2005;252:672-6.

79. Popperl AF, Noll F. Diagnostic value of serological test-systems used in diagnosis of infection with Borrelia burgdorferi. [German] Diagnostische Wertigkeit serologischer Verfahren bei der Diagnostik einer Infektion mit Borrelia burgdorferi. Lab Med. 2000;24:190-7. German.

80. Roux F, Boyer E, Jaulhac B, Dernis E, Closs-Prophette F, Puechal X. Lyme meningoradiculitis: Prospective evaluation of biological diagnosis methods. Eur J Clin Microbiol Infect Dis. 2007:26:685-93.

81. Skarpaas T, Ljostad U, Sobye M, Mygland A. Sensitivity and specificity of a commercial C6 peptide enzyme immuno assay in diagnosis of acute Lyme neuroborreliosis. Eur J Clin Microbiol Infect Dis. 2007;26:675-7.

82. Skogman $\mathrm{BH}$, Croner $\mathrm{S}$, Forsberg $\mathrm{P}$, Ernerudh J, Lahdenne P, Sillanpaa $\mathrm{H}$, et al. Improved laboratory diagnostics of lyme neuroborreliosis in children by detection of antibodies to new antigens in cerebrospinal fluid. Pediatr Infect Dis J. 2008;27:605-12.

83. Lijmer JG, Mol BW, Heisterkamp S, et al. Empirical evidence of designrelated bias in studies of diagnostic tests. JAMA. 1999:282:10611066.

84. Leeflang MM, Moons KG, Reitsma JB, Zwinderman AH. Bias in sensitivity and specificity caused by data-driven selection of optimal cutoff values: mechanisms, magnitude, and solutions. Clin Chem. 2008;54:729737.

85. Van Burgel ND. Host-pathogen interactions in Lyme disease and their application in diagnostics. 2013. Doctoral Thesis, Leiden University

86. Coumou J, Hovius JW, van Dam AP. Borrelia burgdorferi sensu lato serology in the Netherlands: guidelines versus daily practice. Eur J Clin Microbiol Infect Dis. 2014:33:18031808.

87. Müller I, Freitag MH, Poggensee $\mathrm{G}$, et al. Evaluating frequency, diagnostic quality, and cost of Lyme borreliosis testing in Germany: a retrospective model analysis. Clin Dev Immunol. 2012;2012:595427.
88. Dessau RB, Bangsborg JM, Ejlertsen T, Skarphedinsson S, Schønheyder HC. Utilization of serology for the diagnosis of suspected Lyme borreliosis in Denmark: survey of patients seen in general practice. BMC Infect Dis. 2010;10:317.

89. Bossuyt PM, Reitsma JB, Bruns DE, Gatsonis CA, Glasziou PP, Irwig LM, et al. Standards for Reporting of Diagnostic Accuracy. Towards complete and accurate reporting of studies of diagnostic accuracy: the STARD initiative. BMJ. 2003;326:41-4.

90. Coumou J, Herkes EA, Brouwer MC, van de Beek D, Tas SW, Casteelen G, van Vugt M, Starink MV, de Vries HJ, de Wever B, Spanjaard L, Hovius JW. Ticking the right boxes: classification of patients suspected of Lyme borreliosis at an academic referral center in the Netherlands. Clin Microbiol Infect. 2015;21(4):368. e11-20.

91. De Pauw B, Walsh TJ, Donnelly JP, et al. Revised definitions of invasive fungal disease from the European Organization for Research and Treatment of Cancer/Invasive Fungal Infections Cooperative Group and the National Institute of Allergy and Infectious Diseases Mycoses Study Group (EORTC/MSG) Consensus Group. Clin Infect Dis. 2008;46(12):1813-21.

92. Rutjes AW, Reitsma JB, Coomarasamy A, Khan KS, Bossuyt PM. Evaluation of diagnostic tests when there is no gold standard. A review of methods. Health Technol Assess. 2007;11:iii. ix-51.

93. Lord SJ, Irwig L, Bossuyt PM. Using the principles of randomized controlled trial design to guide test evaluation. Med Decis Making. 2009;29:E1-E12.

\section{Submit your next manuscript to BioMed Central and we will help you at every step:}

- We accept pre-submission inquiries

- Our selector tool helps you to find the most relevant journal

- We provide round the clock customer support

- Convenient online submission

- Thorough peer review

- Inclusion in PubMed and all major indexing services

- Maximum visibility for your research

Submit your manuscript at www.biomedcentral.com/submit
) Biomed Central 